\title{
Force-displacement response of in-plane-loaded URM walls with a dominating flexural mode
}

\author{
Sarah Petry and Katrin Beyer*,† \\ Earthquake Engineering and Structural Dynamics (EESD), School of Architectural, Civil and Environmental \\ Engineering (ENAC), École Polytechnique Fédérale de Lausanne (EPFL), Lausanne, Switzerland
}

\begin{abstract}
SUMMARY
This article presents a new mechanical model for the non-linear force-displacement response of unreinforced masonry (URM) walls developing a flexural rocking mode including their displacement capacity. The model is based on the plane-section hypothesis and a constitutive law for the masonry with zero tensile strength and linear elastic behaviour in compression. It is assumed that only the compressed part of the wall contributes to the stiffness of the wall and therefore the model accounts for a softening of the response due the reduction of the effective area. Stress conditions for limit states are proposed that characterise the flexural failure. The new model allows therefore linking local performance levels to global displacement capacities. The limit states criteria describe the behaviour of modern URM walls with cement mortar of normal thickness and clay bricks. The model is validated through comparison of local and global engineering demand parameters with experimental results. It provides good prediction of the effective stiffness, the force capacity and the displacement capacity of URM walls at different limit states. Copyright (C) 2015 John Wiley \& Sons, Ltd.
\end{abstract}

Received 30 September 2014; Revised 19 April 2015; Accepted 10 May 2015

KEY WORDS: unreinforced masonry; flexural rocking; walls; displacement capacity; effective stiffness

\section{INTRODUCTION}

Previous generations of seismic design codes were based on force-based design approaches, which led in general to conservative designs and evaluations. For the assessment of existing buildings, this is often undesirable, and displacement-based methods, which tend to lead to more realistic and less conservative estimates, should be given preference [1]. Displacement-based methods require not only estimates of the stiffness and strength but also of the deformation capacity. While several models exist that provide good estimates of the force capacity of in-plane-loaded unreinforced masonry (URM) walls [2-6], estimating the displacement capacity and the effective stiffness of URM walls is a much more challenging task, which needs further research [1,7]. One approach for improving existing empirical drift capacity models is to consider additional parameters [8-10]. The effective stiffness is currently computed as a fixed ratio of the elastic stiffness [11], which could potentially also be improved by replacing this fixed ratio by an empirical function of several parameters. In the long-term, it seems, however, desirable to move towards mechanical models for the force-displacement response of URM structural elements. Such models would foster an understanding for key parameters that influence the seismic behaviour of URM walls and could also account for the large regional variability of masonry construction through standard material tests.

*Correspondence to: Katrin Beyer, Earthquake Engineering and Structural Dynamics (EESD), School of Architectural, Civil and Environmental Engineering (ENAC), École Polytechnique Fédérale de Lausanne (EPFL), Lausanne, Switzerland.

${ }^{\dagger}$ E-mail: katrin.beyer@epfl.ch

The MATLAB code for computing the force-displacement response can be obtained from the authors. 
When URM walls are subjected to lateral in-plane loading, three kinds of failure modes are generally distinguished: rocking failure, diagonal shear failure and sliding failure [2]. In this article, walls developing a rocking failure mode, that is, a flexural failure, are discussed. Flexural failure is dominated by local compression failure of the wall toe [2], and Figure 1 compares the global force-displacement response of a URM wall developing a flexural mode to the stress-strain curve obtained from a simple uniform compression test on a masonry wallette. Despite the brittle behaviour of URM in compression (Figure 1(b)), URM walls developing a flexural mode can develop a significant ductility because of its non-linear elastic behaviour (Figure 1(a)) [2, 12]: a URM wall subjected to a constant normal load $N$ and an increasing lateral force $V$ behaves linear elastically until the minimum stress in the bottom section is equal to zero (Figure 2, $V=V_{e}$ ). The tensile strength of URM is negligible. If $V$ increases, the wall enters therefore the non-linear elastic regime, horizontal cracks start opening at the wall base and the effective section reduces while the flexibility of the wall increases. At the onset of decompression, the base moment is equal to $M_{\mathrm{e}}$ :

$$
M_{e}=\frac{N L}{6}
$$
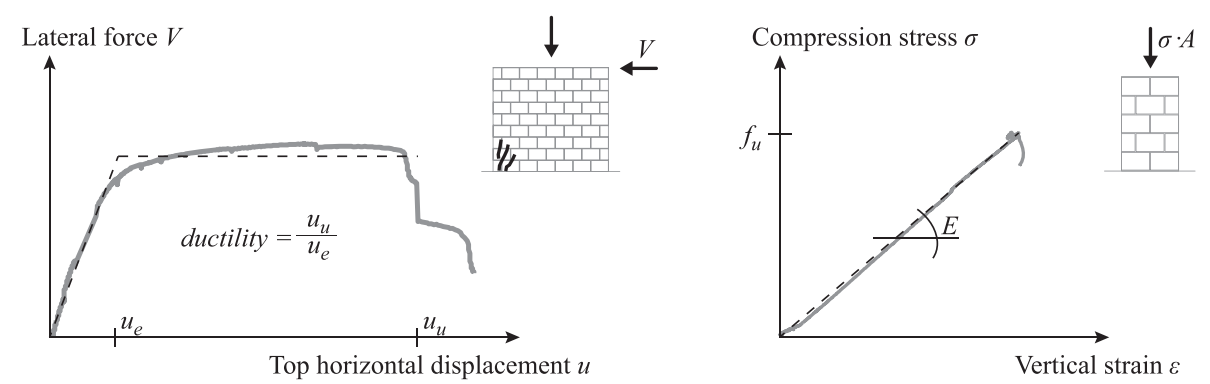

Figure 1. (a) Schematic force-displacement response for a wall developing a flexural rocking mode and (b) stress-strain relationship of masonry in compression.
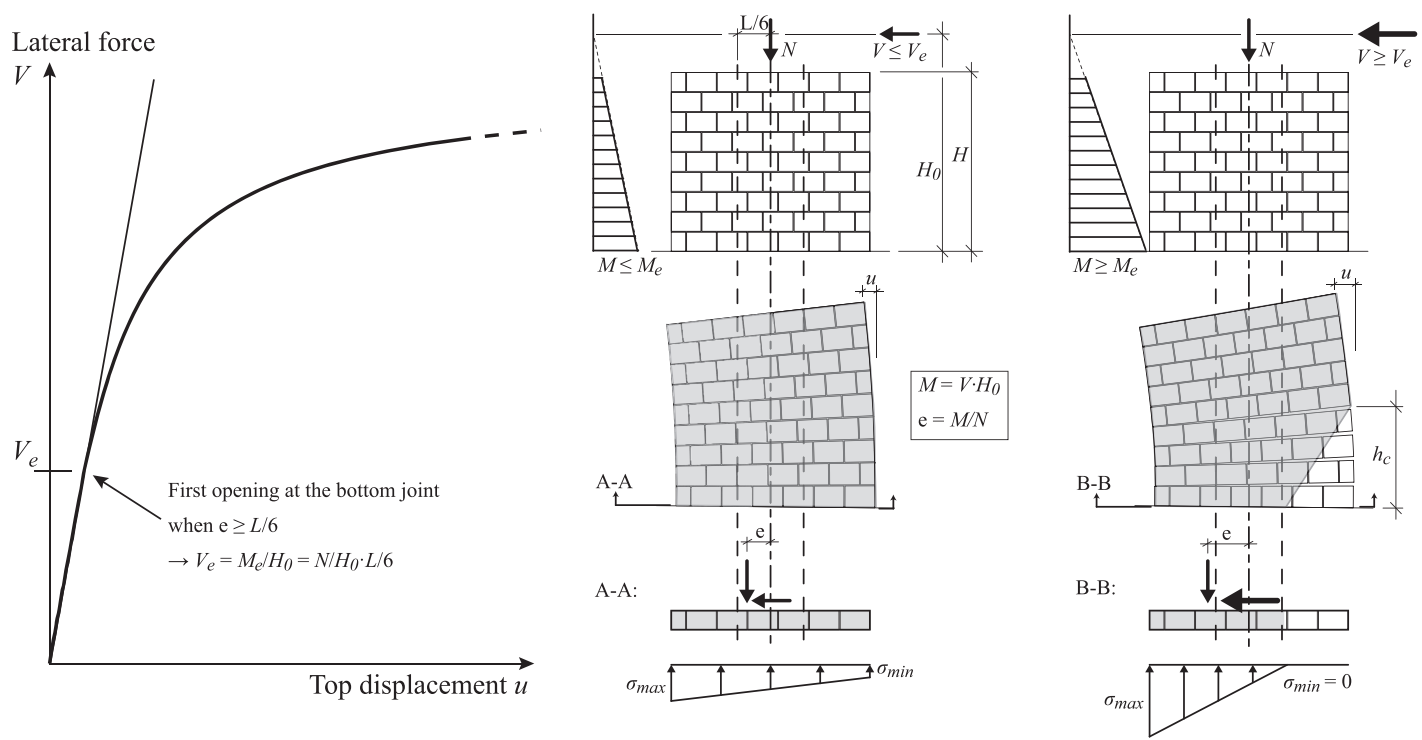

Figure 2. Force-displacement response of a wall assuming a material with zero tensile strength and linear elastic behaviour in compression. 
The corresponding shear force $V_{e}$ is

$$
V_{e}=\frac{N L}{6 H_{0}}
$$

where $N$ is the applied normal load, $L$ the length of the wall and $H_{0}$ the shear span. Several researchers published models that describe the behaviour of flexural URM walls. Some of these models are of analytical nature and derive a direct relationship between horizontal force and top displacement, for example, the force-displacement relationship for leaning towers [13] or the force-displacement response developed in $[14,15]$ and [16]; the latter is implemented as macro-element in the computer software Tremuri [17].

The objective of this paper is to build on these existing models and to propose a model for predicting the force-displacement response of URM walls with a dominating flexural mode that has the following two new features: (i) The shear and flexural flexibility are coupled by basing both on the compressed part of the wall. (ii) New limit state (LS) criteria allow estimating the displacement capacity of masonry walls failing in flexure accounting thereby also for the confining effect of the foundation. The paper is structured as follows: Section 2 reviews the existing models. Based on these models, a new analytical formulation is developed and compared with the existing models in Section 3. In Section 4, local deformation LSs are implemented in the new analytical formulation, and a link between local and global engineering demand parameters (EDPs) is thus established. The model is validated through comparison of local and global EDPs for the experiments presented in Section 5. In Section 6, the model is benchmarked against a larger dataset with regard to the predicted effective stiffness and displacement capacity. In Section 7, the model is used to determine key parameters that influence the ultimate drift capacity. Section 8 concludes the paper with a summary of the findings and an outlook on future research needs.

\section{EXISTING MODELS FOR THE PREDICTION OF THE FORCE-DISPLACEMENT RESPONSE AND THE PERFORMANCE LEVELS OF URM WALLS}

\subsection{Analytical formulations for the force-displacement relationship of URM walls}

Models that estimate analytically the force-displacement response of URM walls were published by Benedetti et al. [14, 15] and by Penna et al. [16]. The model by Benedetti and Steli [14] is based on the plane-section hypothesis and a non-tension material with a linear elastic behaviour in compression. Benedetti and Steli [14] describe the force-displacement behaviour of URM walls in two parts: the linear elastic part before the onset of decompression and the non-linear elastic domain with opening of the base joint (see also Figure 2). The model is derived for flexure-dominated walls but includes also linear elastic shear deformations (although_as the comparison in Section 3.4 will show-these are underestimated). Benedetti and Benedetti implemented a shear failure criterion into the existing model [15], but because damage due to shear solicitation is not considered, the model's application remains restricted to walls whose response is dominated by flexure. The model developed by Penna et al. [16] is based on the idea of separating the wall into a central part and two interfaces at the bottom and top of the wall. Shear deformations are allocated to the central part of the wall and flexural deformations to the interfaces. Section 3.4 contains a detailed discussion of the differences between both models and the new proposed model.

\subsection{Mechanical models for the prediction of the displacement capacity at certain performance levels}

Models that use local performance limits for predicting the global displacement capacity of URM walls were published by Benedetti and Steli [14] and Priestley et al. [12]. The two models have in common that they link local deformation and strength limits in the compressed toe with the global displacement capacity of flexural walls. Benedetti and Steli [14] predict in conjunction with their analytical formulation described in Section 2.1 the yield and ultimate displacement. The model by Priestley et al. [12] gives a direct estimate for the ultimate drift capacity. Both models are based on the 
assumption of an elastic plastic material in the compression zone with a maximum compression strain of $3 \%$ and $4 \%$, respectively. A more detailed review of these models can be found in [18].

\section{NEW ANALYTICAL FORMULATION FOR THE ELASTIC FORCE-DISPLACEMENT RELATIONSHIP FOR URM WALLS}

Benedetti and Steli [14] developed an analytical formulation for the elastic force-displacement relationship of cantilever walls subjected to an increasing horizontal load and a constant vertical load. For walls subjected to fixed-fixed boundary conditions, Benedetti and Steli [14] propose calculating the displacement at half height of the wall and doubling it to obtain the displacement at the top of the wall. In real structures, the boundary conditions of a wall are often different to those of a cantilever or fixed-fixed boundary conditions $[8,10]$. Hence, in the following section, the model is extended for a general normalised shear span $\alpha=H_{0} / H$. Shear and flexural deformations are treated separately in Sections 3.1 and 3.2, respectively. At any point of loading, the total horizontal displacement $u$ can be computed as the sum of the displacements due to flexural and shear deformations:

$$
u=u_{f l}+u_{s h}
$$

Shear deformations are assumed to contribute only to the horizontal displacement but not to the vertical displacement $w$ or the top rotation $\theta$. Hence, the rotation at the top of the wall and the vertical displacement are treated in Section 3.1. The sign convention of all deformation quantities is illustrated in Figure 3. Sections 3.1 and 3.2 apply to walls with $\alpha \geq 1.0$. The computation of the global deformation quantities $u, w$ and $\theta$ for walls with a normalised shear span $\alpha<1.0$ is discussed in Section 3.3.

\subsection{Deformation quantities caused by flexural solicitations for $\alpha \geq 1.0$}

Based on the plane-section hypothesis and a non-tension material, the following relationship is obtained between the length of the compression zone $L_{c}$ and the base moment $M$ (Figure 2):

$$
L_{c}=L \text { for } M \leq M_{e}
$$

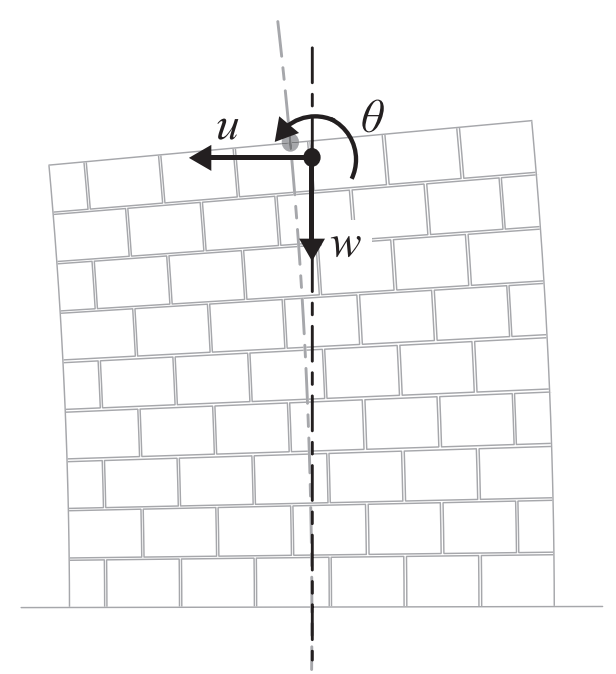

Figure 3. Definition and sign convention for the three global deformation quantities $u, w$ and $\theta$. 


$$
L_{c}=3\left(\frac{L}{2}-\frac{M}{N}\right) \text { for } M>M_{e}
$$

Considering further the linear elastic material behaviour of the masonry in compression (Figure 1(b)), the curvature after onset of decompression is estimated as follows:

$$
\begin{gathered}
\chi=\frac{M}{E I} \text { for } M \leq M_{e} \\
\chi=\frac{2 N}{E T} \cdot \frac{1}{L_{c}{ }^{2}} \text { for } M>M_{e}
\end{gathered}
$$

where $T$ is the thickness of the wall, $I=L^{3} T / 12$ is the moment of inertia of the full section and $E$ is the $E$ modulus for loading perpendicular to the bed joints.

Assuming a simple Bernoulli beam with a constant section along its length for $V \leq V_{e}$ and a varying section for $V>V_{e}$, the flexural displacement $u_{f}$ is derived as follows:

$$
\begin{gathered}
u_{f l}=V \cdot \frac{H^{3}}{2 E I}\left(\alpha-\frac{1}{3}\right) \text { for } V \leq V_{e} \\
u_{f l}=u_{e, f l} \cdot\left(\left(1-\frac{\alpha^{2}(3-\alpha)}{3 \alpha-1}\right) \cdot \frac{V}{V_{e}}+\frac{3 \alpha^{2}(1-\alpha)}{3 \alpha-1} \cdot \frac{V_{e}}{V}+\frac{2 \alpha^{3}}{3 \alpha-1} \cdot\left(\frac{V_{e}}{V}\right)^{2}\right)+\theta_{c r}(V) \cdot\left(H(1-\alpha)+\frac{M_{e}}{V}\right) \\
+\psi_{c r}(V) \text { for } V>V_{e}
\end{gathered}
$$

with

$$
\begin{gathered}
\theta_{c r}(V)=-\frac{2 N^{2}}{9 E T L V}(\mu-6 \eta) \\
\psi_{c r}(V)=-\frac{N^{3}}{9 E T V^{2}}\left(\frac{2}{3} \mu-4 \eta+2 \ln \left(\frac{2}{3} \mu\right)\right) \\
\mu=\frac{L \cdot N}{L \cdot N-2 \alpha H \cdot V} \\
\eta=\frac{\alpha H \cdot V}{L \cdot N-2 \alpha H \cdot V}
\end{gathered}
$$

where $H$ is the height of the URM wall. $u_{e, f}$ is the flexural displacement at $V=V_{e}$ and is computed using Eqs (2) and (8). In addition to a horizontal displacement, the vertical strains cause also the top of the wall to move vertically and to rotate. The rotation $\theta$ at the top of the wall equates to

$$
\begin{gathered}
\theta=\frac{V}{E I} H^{2}\left(\alpha-\frac{1}{2}\right) \text { for } V \leq V_{e} \\
\theta=\frac{V}{2 E I} H^{2}\left(-(1-\alpha)^{2}+\left(\alpha \cdot \frac{V_{e}}{V}\right)^{2}\right)+\theta_{c r}(V) \text { for } V>V_{e}
\end{gathered}
$$


and the vertical displacement $w$ to

$$
\begin{gathered}
w=\frac{N H}{E L T} \text { for } V \leq V_{e} \\
w=w_{e} \cdot(1-\alpha)+\frac{2 N^{2}}{9 E T V}\left(\frac{9}{4}-\mu+3 \ln \left(\frac{2}{3} \mu\right)\right) \text { for } V>V_{e}
\end{gathered}
$$

\subsection{Deformation quantities caused by shear solicitations for $\alpha \geq 1.0$}

Assuming that only the compressed section contributes to the shear stiffness of the wall, the shear behaviour as the flexural behaviour will be influenced by the reduction of the effective section, and the following relationship between the equivalent shear strain and the lateral load is derived:

$$
\gamma=\frac{6 V}{5 G T} \cdot \frac{1}{L_{c}}
$$

where $G$ is the shear modulus and $L_{c}$ the compression length according to Eqs (4) or (5). Hence, assuming a simple Timoshenko beam with constant section along its length for $V \leq V_{e}$, a varying section for $V>V_{e}$ and by integrating the equivalent shear strain computed with Eq. (18), the following relationship is established between shear displacement $u_{s h}$ and $V$ :

$$
\begin{gathered}
u_{s h}=V \cdot \frac{6 H}{5 G A} \text { for } V \leq V_{e} \\
u_{s h}=u_{e, s h} \cdot\left(\alpha+\frac{V}{V_{e}}(1-\alpha)\right)+\psi_{s h}(V) \text { for } V>V_{e}
\end{gathered}
$$

with

$$
\begin{gathered}
\psi_{s h}(V)=\frac{2 N}{5 G T} \cdot \ln \left(\frac{2}{3} \mu\right) \\
\mu=\frac{L \cdot N}{L \cdot N-2 \alpha H \cdot V}
\end{gathered}
$$

where $A=L T$ is the area of the full section.

\subsection{Extension of the model to normalised shear spans of $\alpha=H_{0} / H \leq 1.0$}

By applying the following procedure, the new model can be applied also to walls with a shear span smaller than the wall height. First, the horizontal displacement $u_{1,0}$ at the inflection point is computed using Eqs (8) to (22) by replacing the wall height by the shear span and setting the normalised shear span to one, hence $H^{*}=H_{0}$ and $\alpha^{*}=1$. In a second step, the rotation $\theta_{1,0}$ and the vertical displacement $w_{1,0}$ at the inflection point are computed using Eqs (14) to (17) setting again $H^{*}=H_{0}$ and $\alpha^{*}=1$.

The relative horizontal displacement between inflection point and top, $u_{2,0}$, is obtained using again Eqs (8) to (22), but replacing this time the wall height by the height remaining above the inflection point and setting the normalised shear span again equal to one, hence $H^{*}=H-H_{0}$ and $\alpha^{*}=1$. Note also that the limit $V \leq l>V_{e}$ changes to $V \leq />H_{0} /\left(H-H_{0}\right) V_{e}$ for the part of the wall above the inflection point. In the next step, the rotation $\theta_{2,0}$ and the vertical displacement $w_{2,0}$ are computed for the part of the wall above the inflection point applying Eqs (14) to (17) again with $H^{*}=H-H_{0}$ and $\alpha^{*}=1$. Finally, the displacements and rotation at the top of the wall are computed as follows: 


$$
\begin{gathered}
u=u_{1,0}+u_{2,0}+\left(\theta_{1,0}-\theta_{2,0}\right) \cdot(H-\alpha H) \\
\theta=\theta_{1,0}-\theta_{2,0} \\
w=w_{1,0}+w_{2,0}
\end{gathered}
$$

\subsection{Extension of the model to normalised shear spans of $\alpha=H_{0} / H \leq 1.0$ and $V>N L /(6 H(\alpha-1))$}

For walls with a shear span larger than 1.5 times the wall height, the moment at the top can exceed the moment at first cracking $\left(M_{\text {top }}>N L / 6\right)$, resulting thus in a reduction of the compression length over the whole height of the wall. This is the case when following condition is fulfilled:

$$
V>\frac{N L}{6 H} \cdot \frac{1}{\alpha-1}
$$

In this case, the deformation quantities $u_{1,0}, w_{1,0}$ and $\theta_{1,0}$ can be computed by extending artificially the wall height to the shear span, hence, while assuming $H^{*}=H_{0}$ and $\alpha^{*}=1$ and using the equations from Sections 3.1 and 3.2. Then, the deformation quantities $u_{2,0}, w_{2,0}$ and $\theta_{2,0}$, which develop in the artificially extended part, are computed while applying $H^{*}=H_{0}-H$ and $\alpha^{*}=1$ to the equations from Sections 3.1 and 3.2. Finally, the displacements and rotation at the top of the wall are computed with the following relationships:

$$
\begin{gathered}
u=u_{1,0}-u_{2,0}-\left(\theta_{1,0}-\theta_{2,0}\right) \cdot(H-\alpha H) \\
\theta=\theta_{1,0}-\theta_{2,0} \\
w=w_{1,0}-w_{2,0}
\end{gathered}
$$

\subsection{Differences between the existing models and the new proposed model}

Figures 4 and 5 compare the predicted force-displacement curves using the new analytical formulation (Eqs (3) to (22)) and the models developed by Benedetti and Steli [14] and by Penna et al. [16] for a cantilever wall $(\alpha=1.0)$. The model by Benedetti and Steli [14] does not provide an estimate for the vertical displacement and the rotation at the top of the wall; thus, for these two parameters, only the model from Penna et al. [16] is compared with the new analytical formulation. Even though all models are based on the same moment-curvature relationship, the resulting force-displacement relationships diverge notably after the onset of decompression in the base joint.

The model by Benedetti and Steli [14] predicts at the onset of the non-linearity an abrupt increase of the flexibility, which is also shown in the graphs reported in [14]. The shape of the curve resembles that of a moment-curvature relationship of reinforced concrete, and it results probably from an error in the integration of the curvature profile. In addition, it can be noted that the model by Benedetti and Steli [14] predicts the shear deformation to decrease after the onset of decompression. As noted in [18], this is not in line with experimental observations. The new analytical formulation accounts for the reduction of the effective section when computing shear deformations, predicting therefore an increase in shear flexibility with the onset of decompression.

In the model by Penna et al. [16], the reduction of the compression zone is only computed at the interfaces at the top and bottom of the wall, that is, where the maximum curvatures develop. This results in an overestimation of the flexural deformation in the linear elastic part $\left(V_{e} \leq V\right)$, and when 

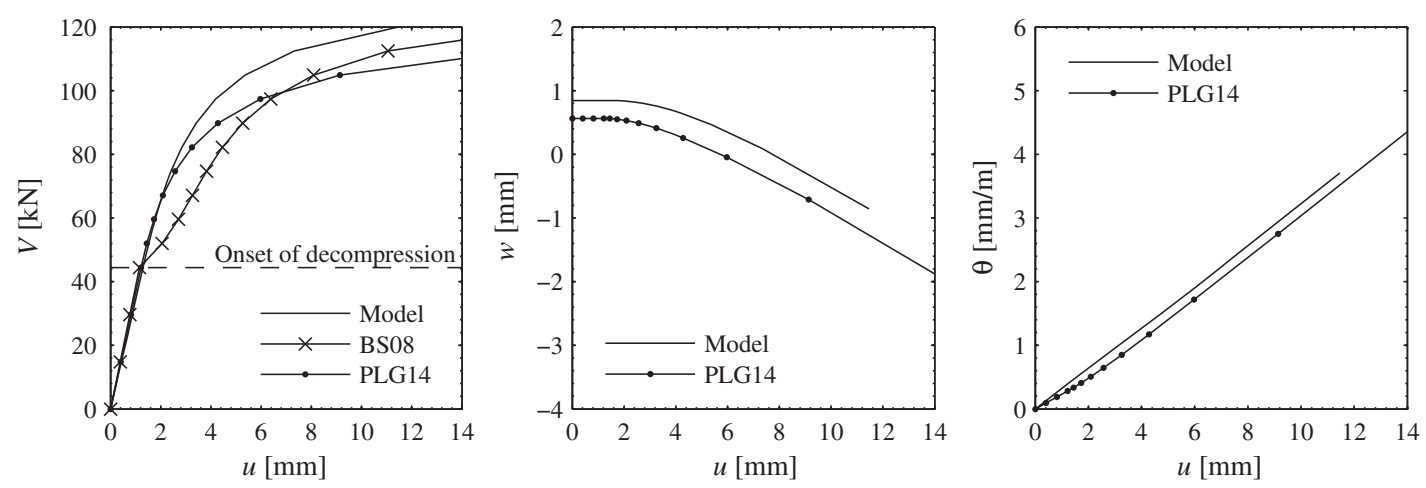

Figure 4. Global deformation quantities for a cantilever wall according to Benedetti and Steli ('BS08') [14], to Penna et al., including the correction factor from Eq. (30) ('PLG14') [16] and to the new proposed model ('Model').
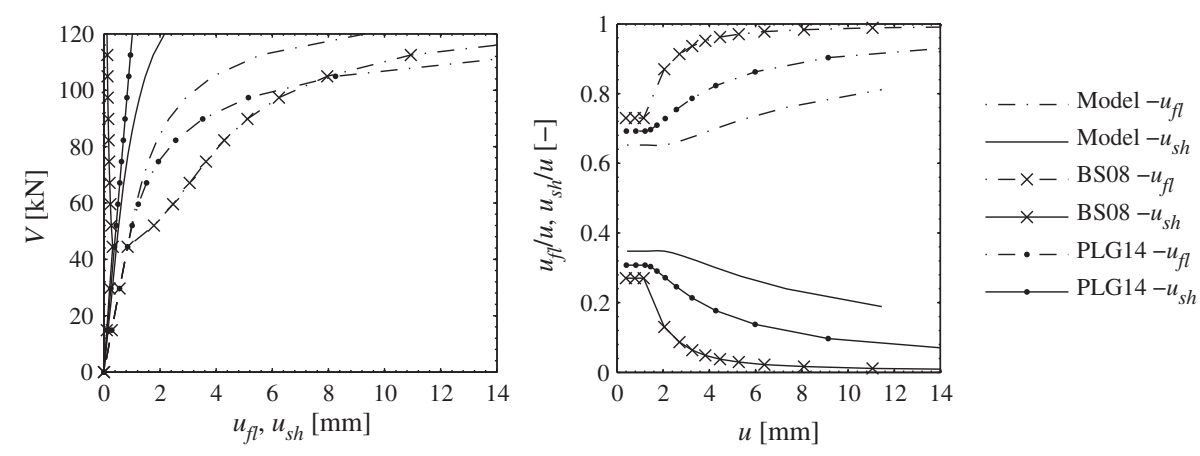

Figure 5. Horizontal displacement components due to shear and flexure for a cantilever wall according to Benedetti and Steli ('BS08') [14], to Penna et al., including the correction factor from Eq. (30) ('PLG14') [16] and to the new proposed model ('Model').

comparing the flexural deformation $u_{f, \text {, PLG }}$ obtained with the model by Penna et al. [16] to a normal Bernoulli beam $u_{B E R}$, the following relationship can be developed:

$$
\frac{u_{f l, P L G}}{u_{B E R}}=\frac{3 \alpha}{3 \alpha-1}
$$

Computing the reduction of the compression zone only at the top and bottom of the wall leads also to a stronger softening of the flexural deformation after the onset of decompression for the model by Penna et al. [16] than for the new model. On the contrary, Penna et al. [16] do not consider the reduction of the compression zone when computing the shear displacement, and the shear forceshear displacement response remains linear elastic throughout the force-displacement curve. Note that Penna et al. [16] also included a damage model [19] that captures the non-linear shear response for shear-dominated walls. This part of the model is not considered here because only flexuredominated walls are treated. The shear displacements estimated with Penna et al. [16] are 20\% smaller with respect to the linear elastic estimation obtained with the new analytical formulation. The new model includes a factor of $6 / 5$ that accounts for the shear stress distribution of a rectangular cross-section (Eq. (18)), which is not included by Penna et al. [16].

\section{IMPLEMENTATION OF LOCAL LIMIT STATES IN THE GLOBAL FORCE- DISPLACEMENT RELATIONSHIP}

The new analytical formulation is based on the assumption of a linear elastic material in compression with zero tensile strength and the hypothesis of plane sections remaining plane. Note that this second 
assumption only holds as long as no significant diagonal crack separates the walls [20]; this limits the application of the model to walls with a dominating flexural mode. For determining the displacement capacity of flexure-dominated URM walls, local LSs need to be predicted as well as their influence on the kinematics of the wall implemented in the model from Section 3. In Table I, a set of local LSs is summarised, which is typically observed for a modern URM wall that is (i) constructed with hollow clay bricks and normal cement mortar, (ii) subjected to lateral in-plane loading and (iii) whose behaviour is dominated by flexure. LS-F2 does not alter the global force-displacement response of the wall and is therefore not considered in the following. LS-F4 results in a significant loss in lateral force capacity, and it can be assumed that this LS is equal to the performance level 'Near Collapse' according to Eurocode 8-Part 3 (EC8-P3) [11]. In the following, the characteristics of the LS-F1, F3 and F4 are discussed, and local performance limits are proposed that allow estimating the global displacement at these LSs.

\subsection{Appearance of first horizontal cracks in bed joints (LS-F1)}

The first appearance of a horizontal crack (LS-F1) is related to the onset of decompression in the base joint. The effect of decompression is considered in the model through the reduction of the effective section. The onset of decompression is reached when $V_{\mathrm{F} 1}=V_{e}$ and the deformation vector at LS-F1 can be computed using Eqs (2), (8), (14), (16) and (19).

\subsection{First splitting cracks in bricks in the compression toe (LS-F3)}

When the horizontal displacement is increased, at a certain point, vertical splitting cracks appear in the bricks of the compressed toe. Observations showed that cracks in bricks initiate often at the second bed joint $\left(y=h_{B}\right.$, Figure 6) and not always as one might expect at the base joint $(y=0)$. This is due to the confining effect of the foundation: masonry subjected to compression fails because of tensile failure of the bricks because mortar has a larger Poisson's ratio than bricks. At the base, the foundation confines the mortar layer and hinders the mortar from expanding. Hence, the typical tensile failure of the brick is observed only in relation to the second bed joint and not to the base joint. Furthermore, cracks initiating from the second joint develop typically first half a brick width inwards from the external fibre of the wall. This is because half bricks at the end of a row-irrespective whether they are in the first or second layer of bricks-have a certain flexibility to rotate inside the matrix of the surrounding mortar joints. Hence, considering the maximum masonry compression strength at the extreme fibre of the second mortar joint leads to too conservative estimates of the displacement capacity associated with LS-F3. This displacement capacity was found to correlate better with the instant when the masonry compression strength $f_{u}$ is reached in the second joint $\left(y=h_{B}\right)$ at a half-brick inwards $\left(x=l_{B} / 2\right)$ from the external fibre:

$$
\sigma_{y}\left(\frac{l_{B}}{2} ; h_{B}\right)=f_{u}
$$

where $\sigma_{y}(x, y)$ is the vertical stress at the horizontal distance $x$ from the extreme fibre at the height $y$ of the wall. $l_{B}$ is the length of the brick plus the width of one vertical mortar joint, and $h_{B}$ is the height of the brick plus the thickness of one horizontal mortar joint.

Table I. Local limit states for in-plane-loaded URM walls with a dominating flexural mode [20].

\begin{tabular}{|c|c|c|}
\hline Limit state & Local crack pattern & Influence on global response \\
\hline LS-F1 & First appearance of a crack in a bed joint & First reduction of stiffness \\
\hline LS-F2 & $\begin{array}{l}\text { Visible separation of the unloaded zone } \\
\text { from the compression zone [13] }\end{array}$ & $\begin{array}{l}\text { Negligible influence on force-displacement } \\
\text { relationship }\end{array}$ \\
\hline LS-F3 & $\begin{array}{l}\text { Appearance of vertical splitting cracks } \\
\text { in compressed corner }\end{array}$ & Peak load is typically attained shortly afterwards \\
\hline LS-F4 & $\begin{array}{l}\text { Loss of part of the toe region due } \\
\text { to crushing }\end{array}$ & Significant loss of the lateral resistance \\
\hline LS-F5 & Crushing of entire compression zone & Axial load failure \\
\hline
\end{tabular}




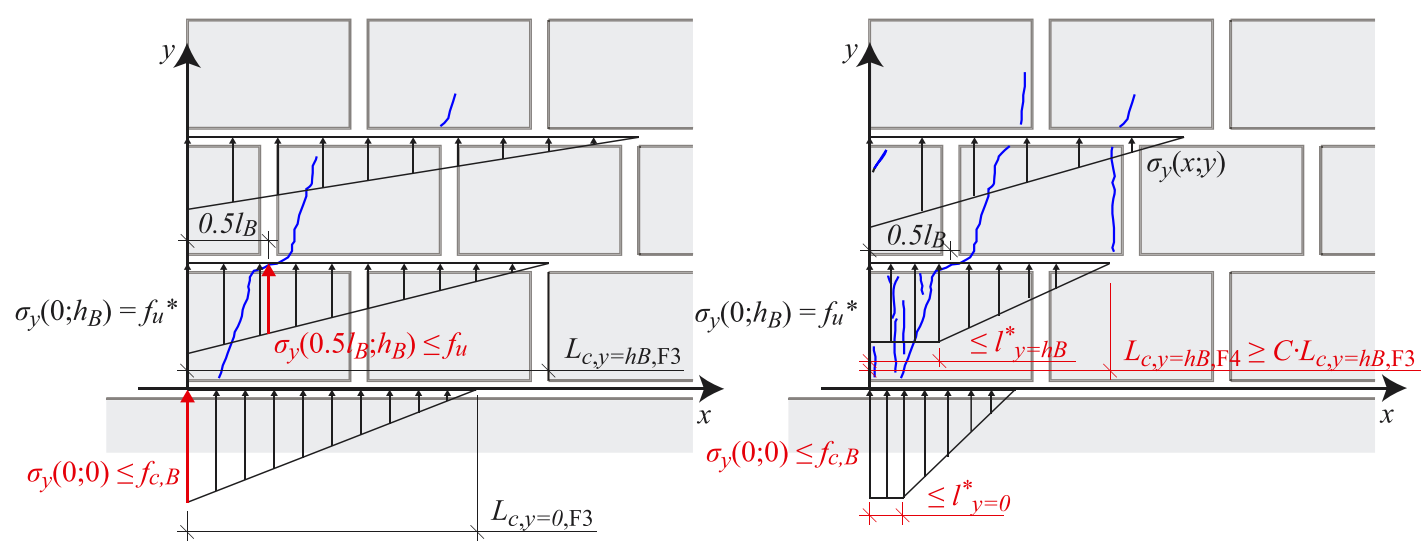

Figure 6. Crack pattern of compressed corner and assumptions for the stress states at (a) first cracks in brick (LS-F3) and (b) at loss of part of the toe region due to crushing (LS-F4).

Depending on the relative size of bricks and walls, the compression stress at the base joint can reach the compression strength of the brick itself before the limit given by Eq. (31) is reached. Therefore, as a second criterion for LS-F3, the compression strength $f_{c, B}$ of the brick has to be considered at the extreme fibre of the base section:

$$
\sigma_{y}(0 ; 0)=f_{c, B}
$$

The two criteria for LS-F3 are illustrated in Figure 6(a). Whichever of the two criteria is reached first will determine the global deformation quantities $u_{\mathrm{F} 3}, w_{\mathrm{F} 3}$ and $\theta_{\mathrm{F} 3}$ at LS-F3, which can be computed using the equations given in Section 3 for $V>V_{e}$. Note that when LS-F3 occurs in the base joint, it is assumed that the ultimate capacity of the wall is reached (i.e., $u_{\mathrm{F} 4}=u_{\mathrm{F} 3}$ ). In that case, Section 4.3 does not apply.

The compression lengths at LS-F3 are required as input parameters for determining LS-F4. They can be computed for the second mortar joint as

$$
L_{c, y=h B, \mathrm{~F} 3}=\frac{N+\sqrt{N^{2}-N \cdot \sigma_{y}\left(\frac{l_{B}}{2} ; h_{B}\right) \cdot T l_{B}}}{f_{u} T}
$$

and for the base joint as

$$
L_{c, y=0, \mathrm{~F} 3}=\frac{2 N}{f_{c, B} T}
$$

\subsection{Loss of part of the toe region due to crushing (LS-F4)}

Experiments showed that walls do not reach lateral load failure with the occurrence of first splitting cracks (LS-F3) but that at this instant, the walls are still able to sustain the applied lateral load and that the load can even increase slightly until first parts of the compression zone break completely apart (LS-F4, [20]).

Figure 6 shows the crack pattern in the compression zone just after reaching LS-F3 (Figure 6(a)) and just before LS-F4 occurred (Figure 6(b)). Between the two LSs, several cracks develop in the corners between the extreme fibre and the splitting crack that initiated at the point $\left(x=l_{B} / 2, y=h_{B}\right)$. This allows a redistribution of the stresses in the compression zone. The maximum length $l^{*}$ over which the stress can redistribute (Figure 6(b)) is assumed to be limited by the aforementioned splitting crack; it can be estimated as follows for the second joint and the base joint: 


$$
\begin{gathered}
l^{*} y=h B \leq \frac{l_{B}}{2} \\
l_{y=0}^{*}=l^{*} y=h B-h_{B} \frac{V_{\mathrm{F} 3}}{N}
\end{gathered}
$$

It is assumed that the continued formation of cracks when loading beyond LS-F3 allows a certain stress redistribution in the compressed toe [20]. The resulting reduction of the compression length at LS-F4 is restricted to account for the limited deformation capacity of masonry in compression. This is accounted for by confining the compression length at LS-F4 to $L_{c, \mathrm{~F} 4} \geq C \cdot L_{c, \mathrm{~F} 3}$, where $C$ should depend on variables that control the deformation capacity of the brick in the post-splitting state (Figure 6(b)). Because experimental evidence on this specific subject is lacking, a value of $C=70 \%$ is proposed. As in LS-F3, one should also account for compression failure of the brick itself, and the maximum stress at the base should be limited to the compression strength $f_{c, B}$ of the brick (Eq. (32)). The different limit criteria for LS-F4 are illustrated in Figure 6(b).

The deformation quantities at LS-F4 are computed as the sum of the deformations $u_{p}, w_{p}$ and $\theta_{p}$, which develop in the zone of vertical splitting cracks and the non-linear elastic deformations $u_{n e}$, $w_{n e}$ and $\theta_{n e}$, which develop in the zone without vertical splitting cracks:

$$
\begin{gathered}
u_{\mathrm{F} 4}=u_{n e}+u_{p}=u_{n e}+\theta_{p} \cdot\left(H-\frac{h_{p}}{2}\right)+u_{s h, p} \\
w_{\mathrm{F} 4}=w_{n e}+w_{p} \\
\theta_{\mathrm{F} 4}=\theta_{n e}+\theta_{p}
\end{gathered}
$$

where $u_{s h, p}$ is the plastic deformation due to shear. $h_{p}$ is the wall height over which vertical splitting cracks in bricks are expected (Figure 7), and it can be estimated as

$$
h_{p}=\frac{V_{\mathrm{F} 4} \cdot H_{0}-M_{F C}}{V_{\mathrm{F} 4}} \geq h_{B}
$$

where $M_{F C}$ is the moment that leads to the first splitting crack and is equal to the moment that triggers LS-F3 $\left(M_{F C}=H_{O}^{*} \cdot V_{\mathrm{F} 3}\right)$ and $H_{0}{ }^{*}$ is the shear span with respect to the critical section, that is, the base joint or the second joint (Figure 7). It is assumed that the vertical splitting cracks form always over at least the height of one brick $\left(h_{B}\right)$. The rotation $\theta_{p}$, which develops in the cracked zone, is computed as follows

$$
\theta_{p}=\left(\chi_{y}=0, \mathrm{~F} 4+\chi_{y}=h p, \mathrm{~F} 4\right) \cdot \frac{h_{p}}{2}
$$

where $\chi_{y}=0, \mathrm{~F} 4$ and $\chi_{y}=h p, \mathrm{~F} 4$ are the curvature at $y=0$ and $h_{p}$, respectively (Figure 7), which can be estimated from the strain at the external fibre (assuming a linear elastic constitutive law as shown in Figure 7) and the compression length:

$$
\begin{gathered}
\chi_{y=0, \mathrm{~F} 4}=\frac{\varepsilon_{y}(0 ; 0)}{L_{c, y}=0, \mathrm{~F} 4}=\frac{2 N}{E T L_{c, y}=0, \mathrm{~F} 4\left(L_{c, y}=0, \mathrm{~F} 4+l^{*}=0\right)} \\
\chi_{y}=h p, \mathrm{~F} 4=\frac{\varepsilon_{y}\left(0 ; h_{p}\right)}{L_{c, y}=h p, \mathrm{~F} 4}=\frac{2 N}{E T L_{c, y}=h p, \mathrm{~F}^{2}}
\end{gathered}
$$




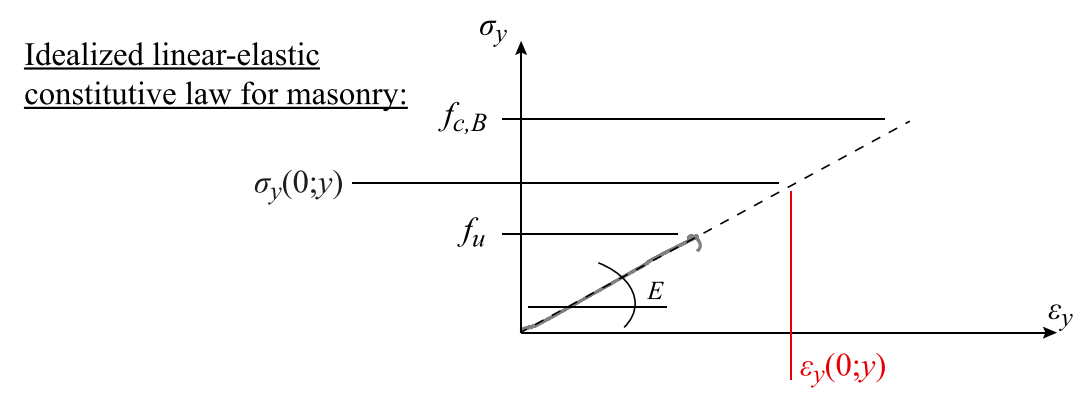

global deformation:

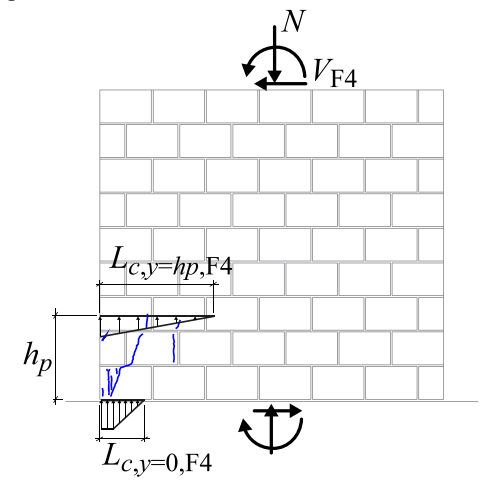

local deformation mechanism:

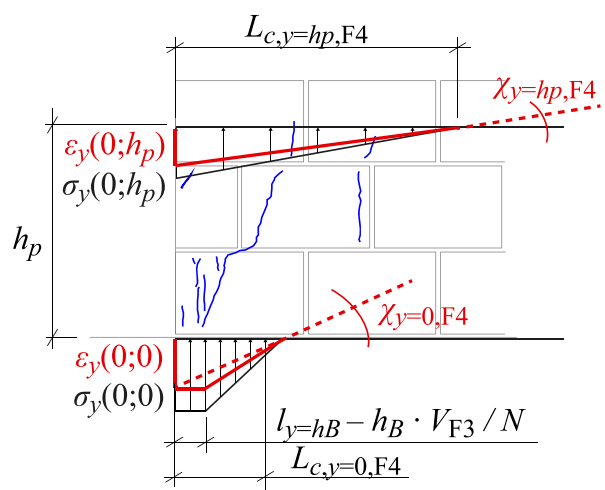

moment:

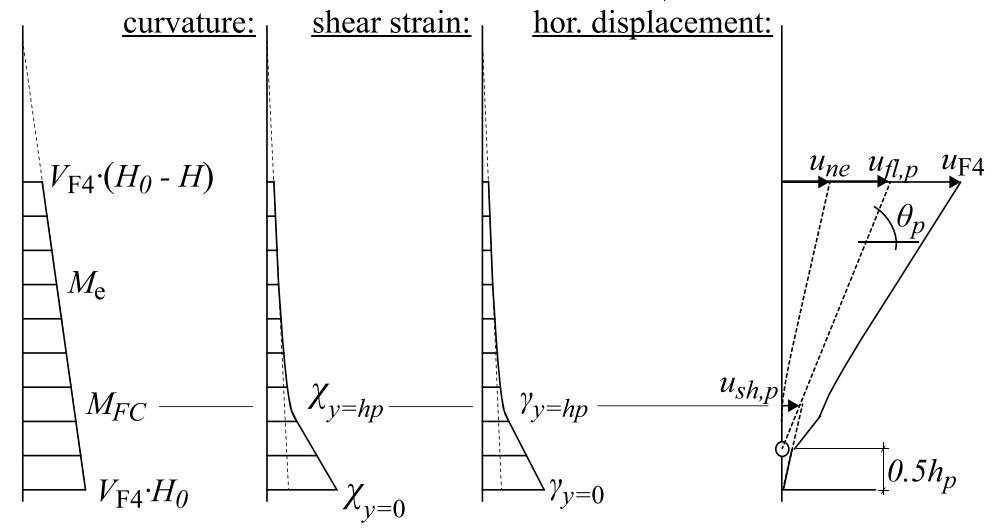

Figure 7. Displacement at LS-F4.

The horizontal displacement component that originates from the shear strain in the zone of splitting can be computed using the same assumptions as in Section 3.2:

$$
u_{s h, p}=\left(\frac{\gamma_{y}=0, \mathrm{~F} 4+\gamma_{y}=h p, \mathrm{~F} 4}{2}\right) \cdot h_{p}=\frac{V_{\mathrm{F} 4}}{2 G T} \cdot\left(\frac{1}{L_{c, \mathrm{y}}=0, \mathrm{~F} 4}+\frac{1}{L_{c, y}=h p, \mathrm{~F} 4}\right) \cdot h_{p}
$$

And the vertical displacement that develops in the splitting zone can be obtained as follows:

$$
w_{p}=\frac{\chi_{y}=0, \mathrm{~F} 4 \cdot\left(L_{c, \mathrm{y}}=0, \mathrm{~F} 4-L / 2\right)+\chi_{y}=h p, \mathrm{~F} 4 \cdot\left(L_{c, \mathrm{y}}=h p, \mathrm{~F} 4-L / 2\right)}{2} \cdot h_{p}
$$

The force-deformation response of all global deformation quantities $(u, w$ and $\theta)$ between LS-F3 and F4 can be estimated by linear interpolation, for example, for the horizontal displacement $u$ :

$$
u=u_{\mathrm{F} 3}+\frac{V-V_{\mathrm{F} 3}}{V_{\mathrm{F} 4}-V_{\mathrm{F} 3}} \cdot\left(u_{\mathrm{F} 4}-u_{\mathrm{F} 3}\right)
$$




\section{EXPERIMENTAL VALIDATION-PART I}

The model is validated in two steps: In this section, the analytical prediction is compared against two tests for which detailed measurements of the displacement field are available. Hence, not only the global response but also the displacement components and local response at the wall base can be compared. In Section 6, the model is validated against a larger set of tests. For these tests, the comparison is based on global EDPs only, that is, effective stiffness, displacement and force capacity.

At École Polytechnique Fédérale de Lausanne, six URM walls were tested under quasi-static cyclic loads; all walls were constructed with hollow clay bricks and normal cement mortar and had dimensions of $L \times H \times T=2.01 \times 2.25 \times 0.20 \mathrm{~m}$ [10, 21]. Two walls of this series developed a significant flexural mode (PUP3 developed a typical flexural rocking and PUP4 showed a hybrid failure mode). These two walls are used in the following for the validation of the mechanical model on the global and local level. Both walls were tested keeping the normal force $(N=419$ and $619 \mathrm{kN}$, respectively) and the shear span constant $\left(H_{0}=1.5\right.$ times the wall height $\left.H\right)$. The material properties that are relevant for the mechanical model are summarised in Table II. The shear modulus could not be determined from experimental tests and was estimated as $25 \%$ of the elastic modulus. Note that current codes, for example, EC-6 [22], estimate the shear modulus as $40 \%$ of the elastic modulus; this is in general considered as too high [23, 24].

\subsection{Global EDPs}

In Figure 8, the force-displacement relationship is estimated for the walls PUP3 and PUP4 using the model presented in Section 3 with the LSs defined in Section 4. Optical measurements taken during the testing of the walls yielded information on the walls' displacement fields. From these measurements, the shear and flexural horizontal displacement components are computed [20] and compared with the predicted displacement components in Figure 9. In Figure 10, the vertical displacement and the top rotation are compared. The figures show that all three degrees of freedom $(u, w$ and $\theta$ ) as well as the shear and flexural components of $u$ are well or very well predicted by the

Table II. Properties of the brick and the masonry for the walls tested at EPFL [21].

Brick properties

Compression tests, II to perforation

$f_{c, B}$

35.0

$\mathrm{MPa}$

Masonry properties

Compression strength

$E$ modulus

Shear modulus

$\begin{array}{lcc}f_{u} & 5.85 & \mathrm{MPa} \\ E & 3550 & \mathrm{MPa} \\ G=0.25 E & 890 & \mathrm{MPa}\end{array}$
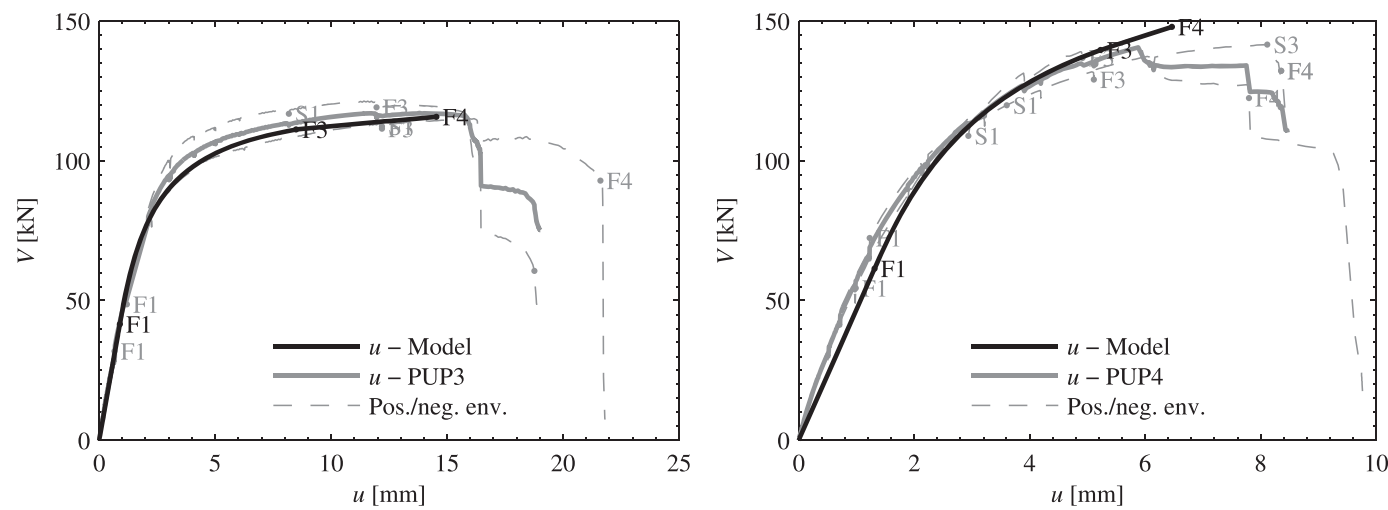

Figure 8. Lateral load versus horizontal displacement. 

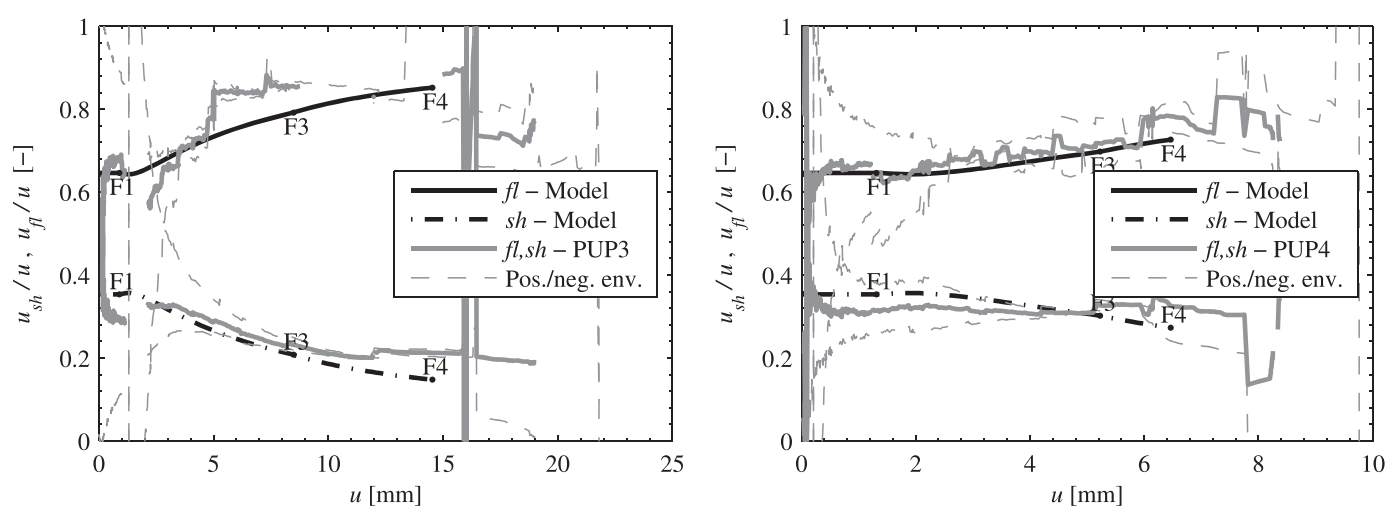

Figure 9. Contributions of the shear and flexural deformations to the total displacement.
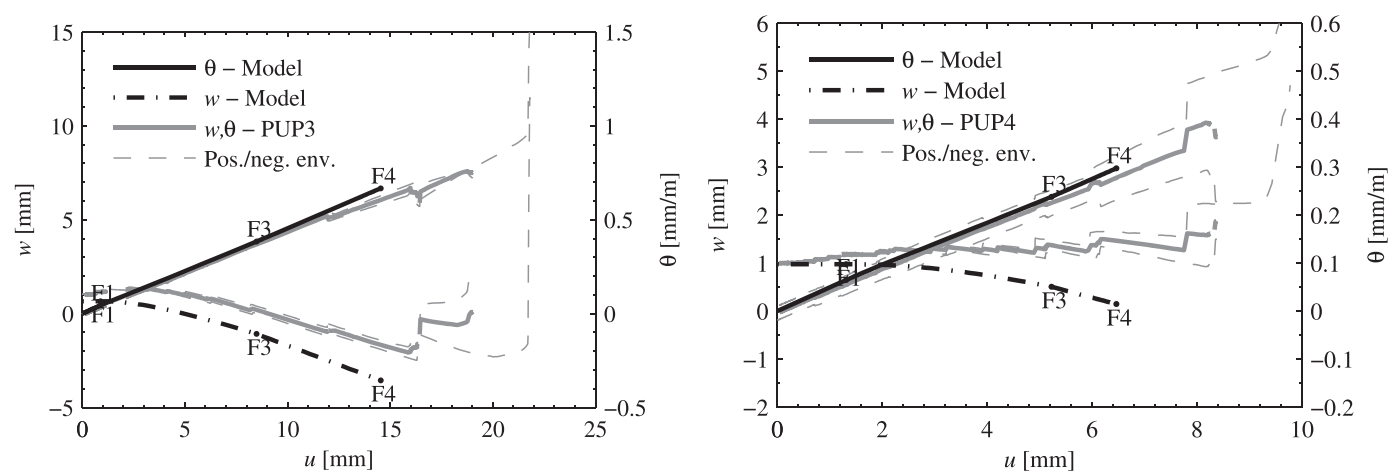

Figure 10. Vertical displacement and top rotation.

model. The largest discrepancies are observed for the vertical displacement, which the model tends to overestimate (Figure 10).

\subsection{Local EDPs}

The key hypotheses of the model are the assumptions (i) that plane section remained plane, (ii) that masonry in compression behaves linear elastically and (iii) that the kinematics of the wall can be represented by a Timoshenko beam with varying cross-section in the linear and non-linear elastic phase (up to LS-F3) and by a plastic hinge model in the plastic phase (LS-F3-F4). To validate these hypotheses, local EDPs are compared with experimental results.

5.2.1. Validation of the plane-section hypothesis and the assumption of the linear elastic behaviour in compression. Figure 11 compares the measured compressed portion of the base joint for the walls PUP3 and PUP4 with the compression length estimated with Eqs (4) and (5). These equations are based on the plane-section hypothesis and a linear elastic material behaviour in compression. Figure 11 shows the measured compression length at the base of the wall as a function of the applied base moment. The measured compression length is determined as the distance from the compressed edge to the location where tension strains are first observed [20]. Equations (4) and (5) should therefore provide a lower bound estimate of this measured compression length, which is confirmed by Figure 11 .

Figure 13 shows the compression strains in the compressed toe; the location of the measurement devices is shown in Figure 12. The strains are estimated at the same locations using the new proposed model, and measurements are compared with theoretical results (Figure 13). It can be seen that an excellent agreement is obtained. From comparison of compression strains and compression length, it can be concluded that the assumptions of plane sections remaining plane and a linear elastic material in compression hold satisfactorily. 

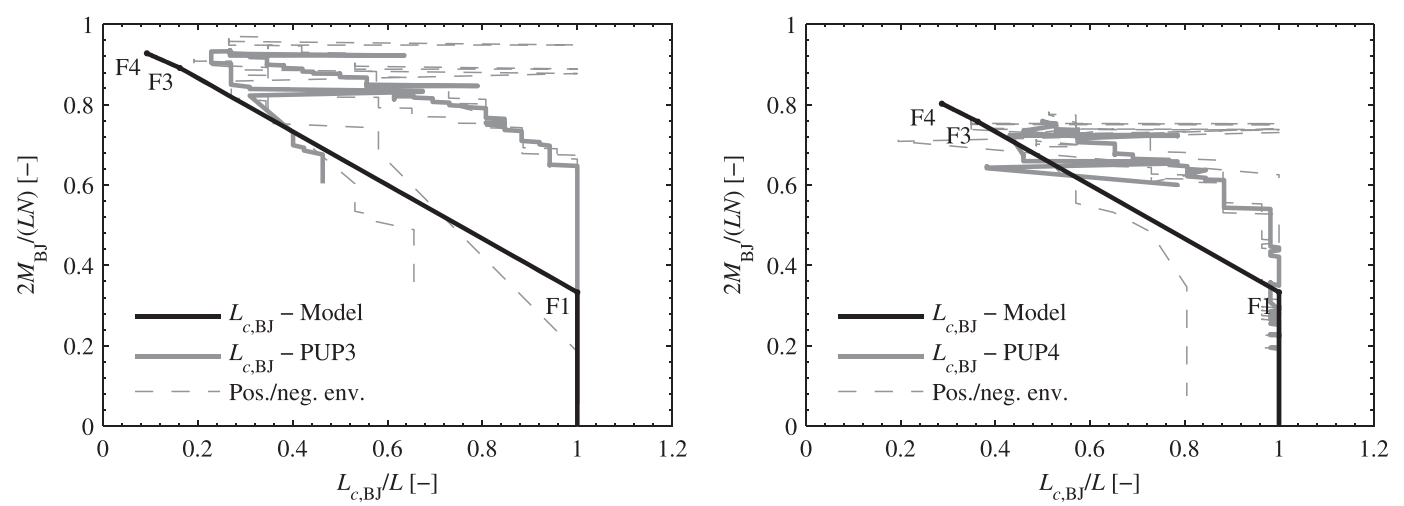

Figure 11. Compression length at the wall base versus moment ratio.

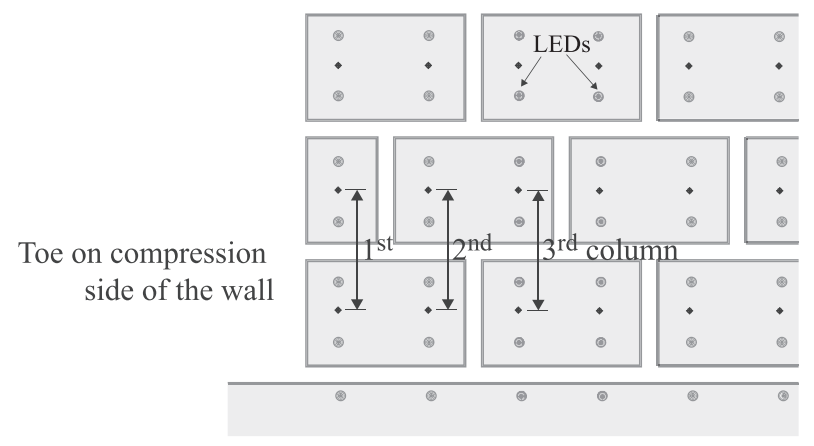

Figure 12. Schema showing the location of strain measurements at the wall toe.
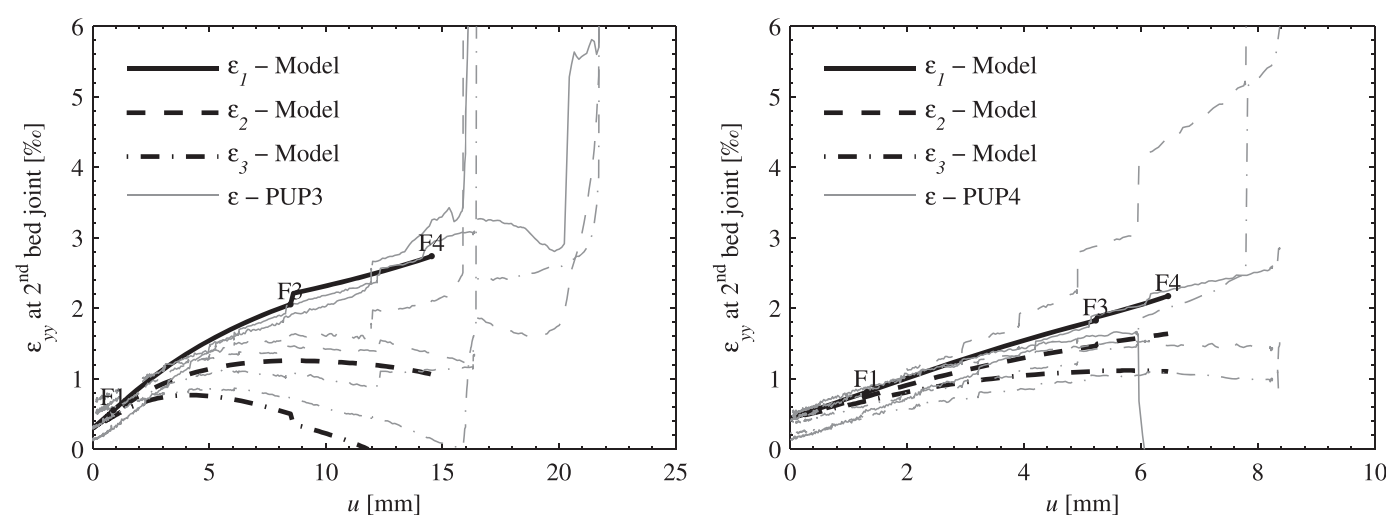

Figure 13. Vertical compression strains in toe base versus lateral top displacement.

5.2.2. Validation of the Timoshenko beam hypothesis. In Figures 14 and 15, the curvature and the average shear strain profiles are estimated when reaching the predicted displacements for the LSs LS-F1, F3 and F4. The experimentally determined profiles are based on the part of the wall that is in compression [20]. The figures show that experimental and theoretical results agree in average well; local deviations can, however, be significant.

5.2.3. Comparison of displacement fields. In Figures 16 and 17, the theoretical deformed shape is estimated integrating the deformation profiles from Section 5.2.2. The unloaded part of the wall is indicated as shaded area. For larger displacements, it can be seen that the predicted displacement field corresponds excellently to the experimentally obtained one. Differences are largest for the 

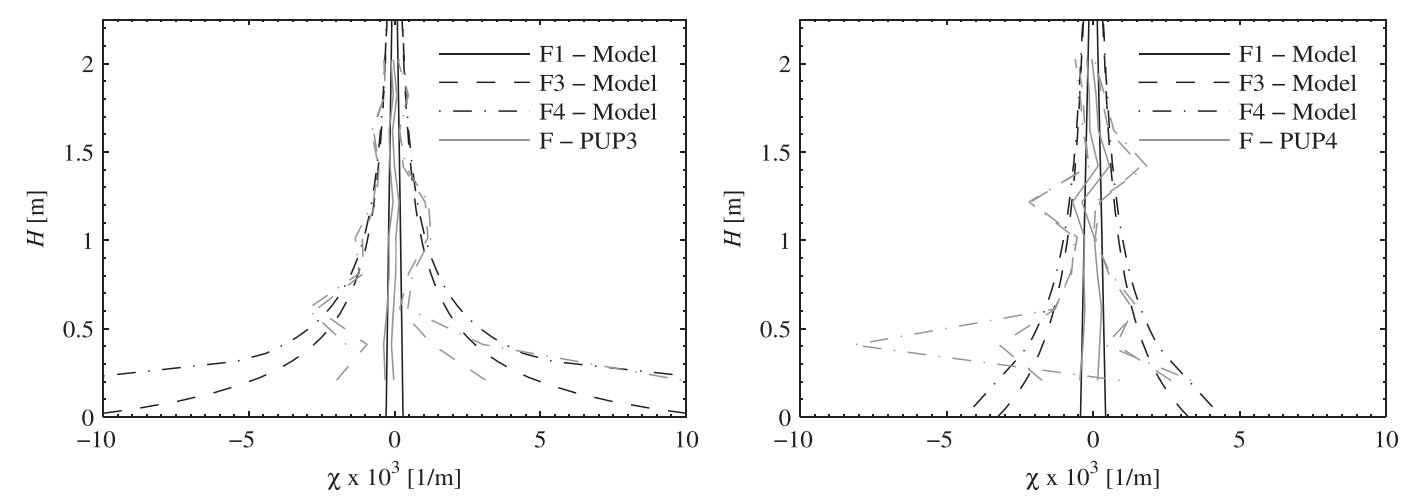

Figure 14. Curvature profiles at LS-F1, F3 and F4.
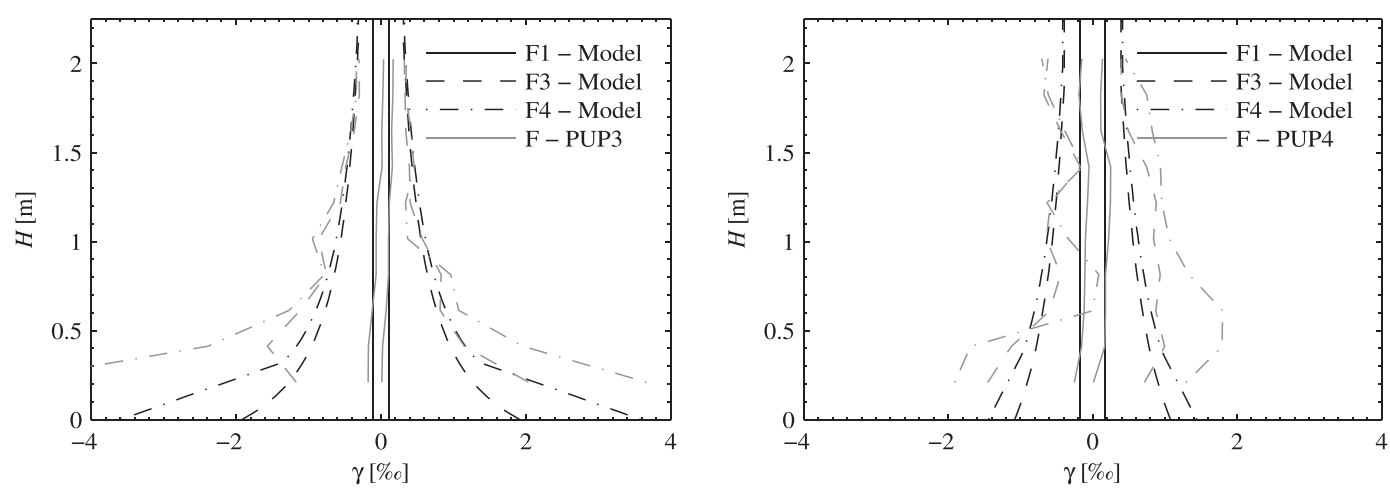

Figure 15. Average shear strains profiles at LS-F1, F3 and F4.

F1

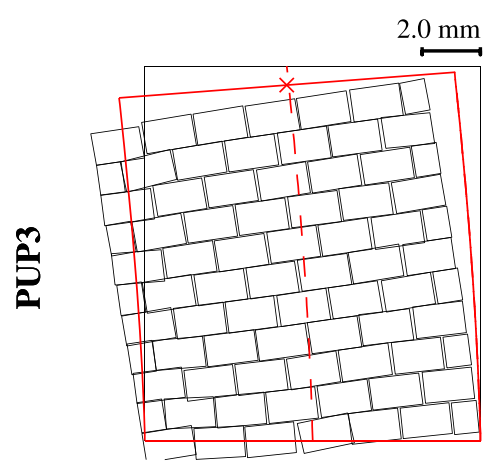

F3

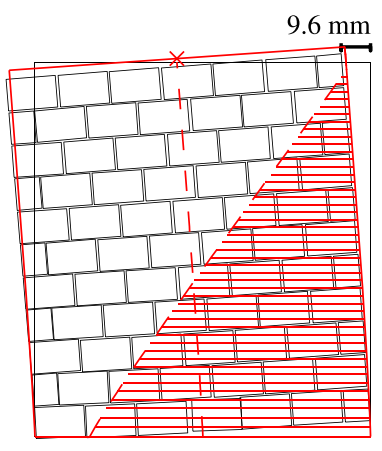

F4

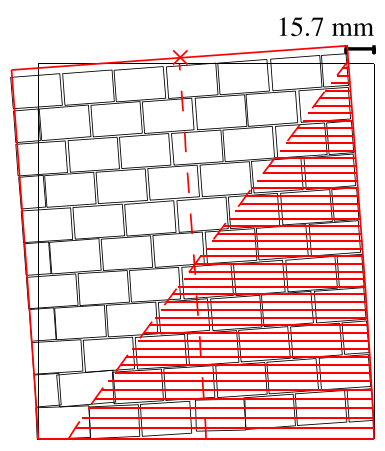

Figure 16. Amplified deformed shapes at the horizontal displacements predicted for LS-F1, F3 and F4 for the wall PUP3 (prediction in red, experimental measurement in black).

vertical displacement, which was also observed in Section 5.1. A comparison of the displacement profiles indicates that the model underestimates somewhat the vertical shortening of the wall.

\section{EXPERIMENTAL VALIDATION-PART II}

In this section, the new proposed model is validated against a larger dataset of modern URM walls [10]. Experimental and theoretical results are compared with regard to the effective elastic stiffness, 
F1

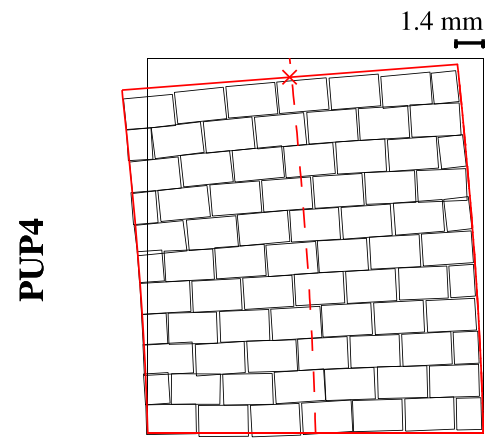

F3

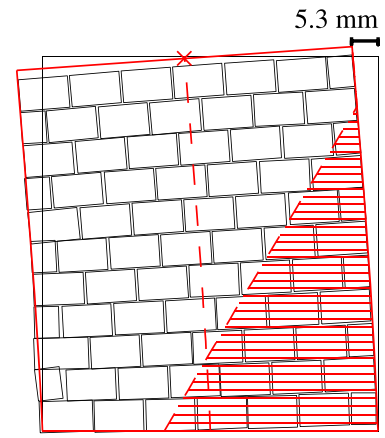

F4

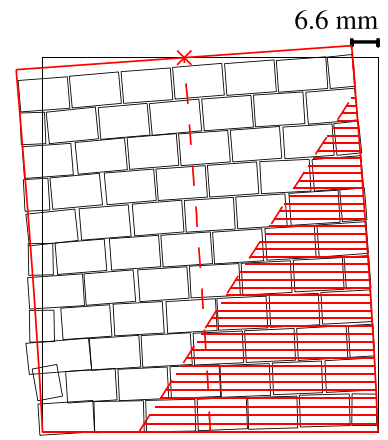

Figure 17. Amplified deformed shapes at the horizontal displacements predicted for LS-F1, F3 and F4 for the wall PUP4 (prediction in red, experimental measurement in black).

the force capacity and the ultimate drift, that is, the three parameters that define the bilinear approximation of the force-displacement response [12]. Hence, the force-displacement curves for the walls from the dataset are computed using the new model, which are then approximated by bilinear curves using the method described in [25]. Therein, the effective stiffness is defined as the secant stiffness at $70 \%$ of the peak force $V_{\max }$ and the ultimate resistance $V_{u l t}$ as the force for which the bilinear approximation yields the same energy as the original curve. The dataset in [10] is based on the dataset by Frumento et al. [25], to which some further wall tests were added. The dataset contains in total 64 walls, which were all tested under quasi-static cyclic or monotonic lateral inplane loading while controlling the level of applied normal force and the shear span. Herein, only the 34 walls are used, which developed a flexural $(\mathrm{F})$ or hybrid $(\mathrm{H})$ failure mode.

For a number of tests, some material properties are unknown, for example, brick strength or elastic modulus of the masonry. For walls for which the compression strength of the brick is unknown, $f_{c}$, ${ }_{B}=25 \mathrm{MPa}$ was initially assumed (all concerned bricks had a void ratio of $40-55 \%$ ). For tests, for which the elastic and shear modulus are not given, these values are estimated from the expected compression strength $f_{u}$. EC8-P3 [11] recommends a factor of 1000 between the characteristic compression strength $f_{k}$ and the $E$ modulus. Assuming $f_{u} / f_{k}=2$, the $E$ modulus can be estimate as $E=500 f_{u}$. The shear modulus is again estimated as $G=0.25 E$ (Section 5).

\subsection{Effective stiffness and strength}

In Figure 18 and Table III, the effective stiffness and strength estimates of the new model are compared with the existing models and code provisions. According to EC8-P3 [11], the effective stiffness can be taken as $50 \%$ of the uncracked stiffness $E I$ and $G A$ and the ultimate resistance as

$$
V_{u l t, E C 8}=\frac{L N}{2 H_{0}}\left(1-1.15 \frac{N}{L T f_{u}}\right)
$$

The model by Penna et al. [16] yields the entire force-displacement response, and the effective stiffness is again determined as the secant stiffness at $70 \%$ of $V_{\max }$. The stiffness was computed using the experimentally determined $E$ modulus applying the additional correction factor (Eq. (30)). As outlined in Section 2.1, Penna et al. [16] tend still to underestimate the wall stiffness after onset of cracking. Figure 18 shows the cumulative distribution of the logarithmic ratio of predicted to experimental value. A ratio of zero corresponds therefore to a perfect match, while ratios smaller (larger) than zero represent samples for which the model underestimates (overestimates) the experimentally obtained value. The figure shows that Eq. (47) tends to underestimate in average slightly the ultimate resistance and that the proposed model yields a better match. However, the differences are small and negligible. The stiffness according to EC8-P3 tends to underestimate the 

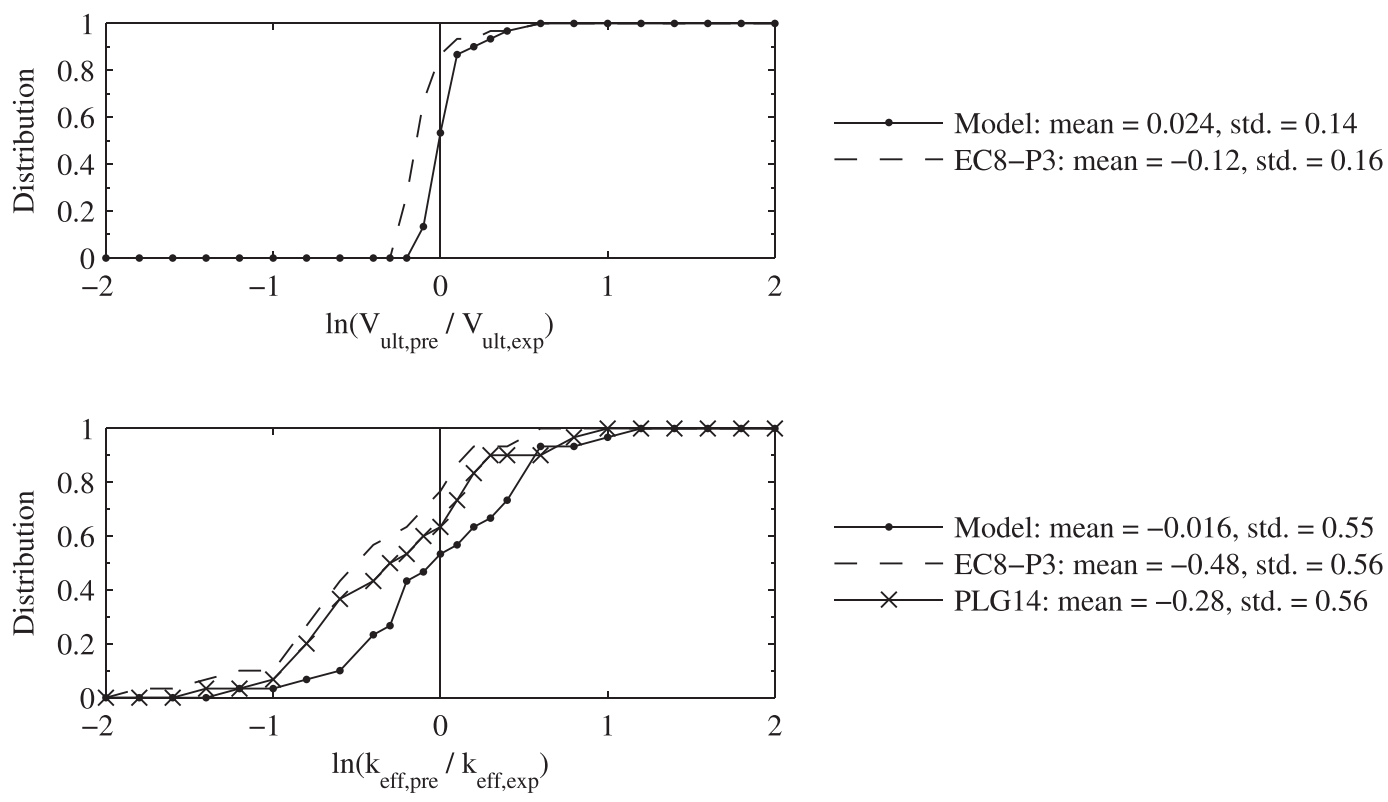

Figure 18. Distribution of the logarithmic ratio between predicted and experimental values of the ultimate lateral resistance $V_{u l t}$ and the effective stiffness $k_{\text {eff }}$ according to the new proposed model ('Model'), to [11] ('EC8-P3') and to [16] ('PLG14').

effective stiffness as does the model by Penna et al. [16]. The latter results from the assumed simplified curvature profile, which is constant over the bottom and top half of the wall. The proposed model on the contrary yields in average a rather accurate prediction of the effective stiffness; the standard variation is, however, similar to the other two models.

\subsection{Displacement capacity at horizontal failure}

Figure 19 shows the comparison of the predicted displacement capacity at the ultimate stage LS-F4 with the displacement capacity obtained from the tests. The experimentally determined displacement capacity is defined as the displacement capacity for which the force dropped by $20 \%$, for example, [25]. It is assumed that the LS LS-F4 corresponds to such a drop in force. The values of the individual test units are summarised in Table III.

For only eight of the tests, the brick strength was known, while for the others, the brick strength was not known. Figure 19 shows the ratio of predicted to observed displacement capacity for the group of tests for which the brick strength was known; for the group of tests for which it was unknown, the prediction was tested for three different values of brick strength $\left(f_{c, B}=15,25,35 \mathrm{MPa}\right)$. The figure shows that the displacement capacity is predicted very well for walls for which the brick strength is known. For walls for which the brick strength is not known, the deviation is significantly larger.

In Figure 20, the displacement capacity at the ultimate stage LS-F4 obtained from the new model is compared with four other drift capacity models: (i) to the displacement capacity given in EC8-P3 [11] of $0.008 \cdot 4 / 3 \cdot H_{0} / L$ for flexural walls, (ii) to the formula proposed in [10] ('PB14'), (iii) to the interstorey drift limit proposed in [12] ('PCK07') and (iv) to the ultimate displacement as defined in [14] ('BS08'). For tests for which the brick strength is not known, the values obtained for the model are based on $f_{c, B}=25 \mathrm{MPa}$. The comparison shows that the new model yields a slightly smaller standard deviation than existing empirical and mechanical models and that in average, it tends to underestimate the displacement capacity. The latter results mainly from small test units, for which the displacement capacity is governed by the stress criterion at the base joint. It indicates that the confining effect of the foundation and its influence on the displacement capacity deserves a more indepth analysis. At present, however, there were no detailed test data on such small walls available. 
FORCE-DISPLACEMENT RESPONSE OF IN-PLANE-LOADED URM WALLS

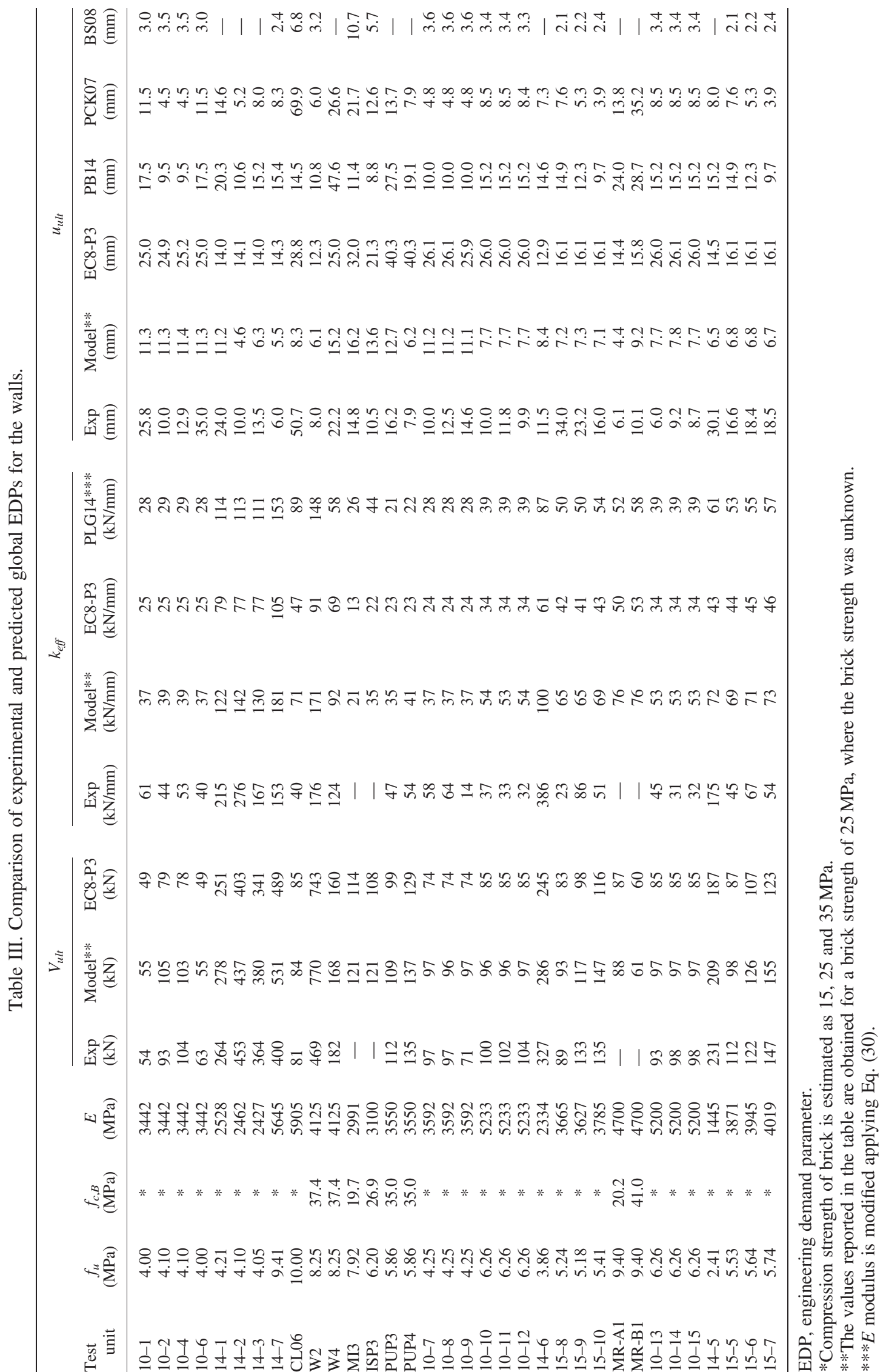




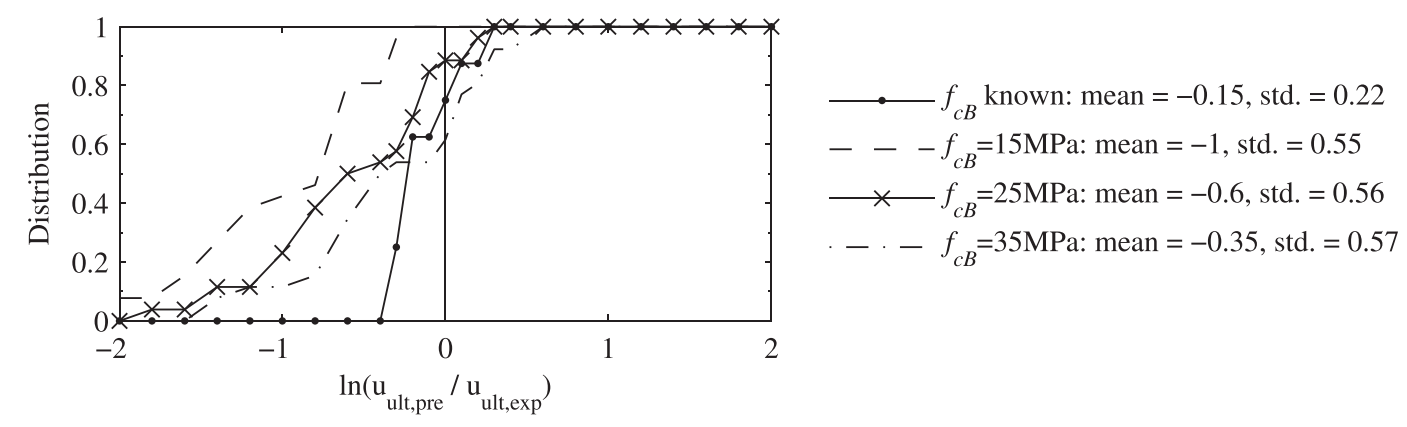

Figure 19. Distribution of the logarithmic ratio between predicted and experimental values of the ultimate displacement $u_{u}$ according to the new proposed model ('Model'), for the walls for which the $f_{c, B}$ was known and for the walls where $f_{c, B}$ was unknown and estimated at $f_{c, B}=15,25$ and $35 \mathrm{MPa}$.

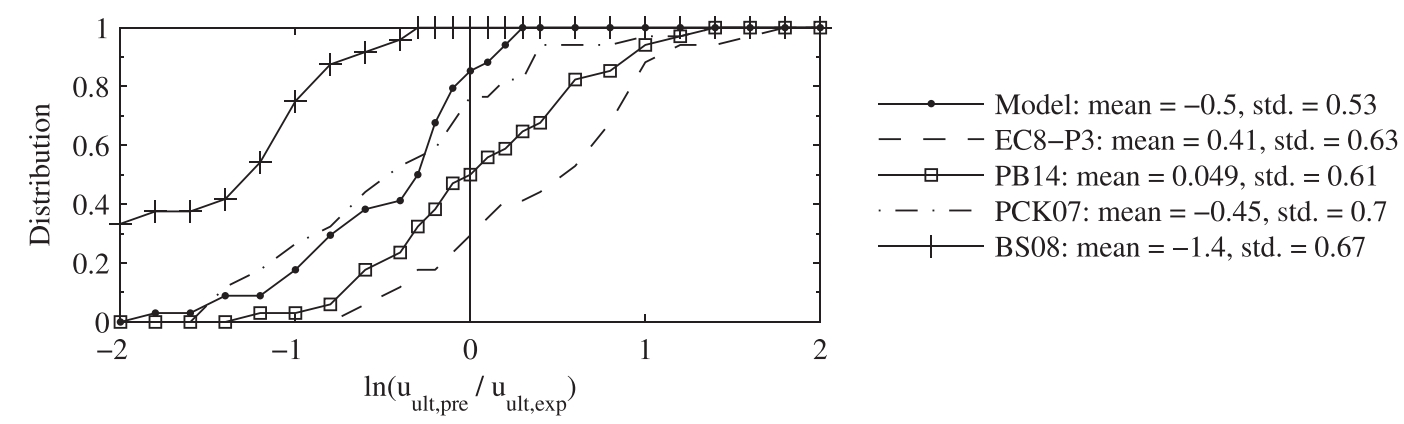

Figure 20. Distribution of the logarithmic ratio between predicted and experimental values of the ultimate displacement $u_{u}$ according to the new proposed model ('Model'), to [11] ('EC8-P3'), to [10] ('PB14'), to [12] ('PCK07') and to [14] ('BS08').
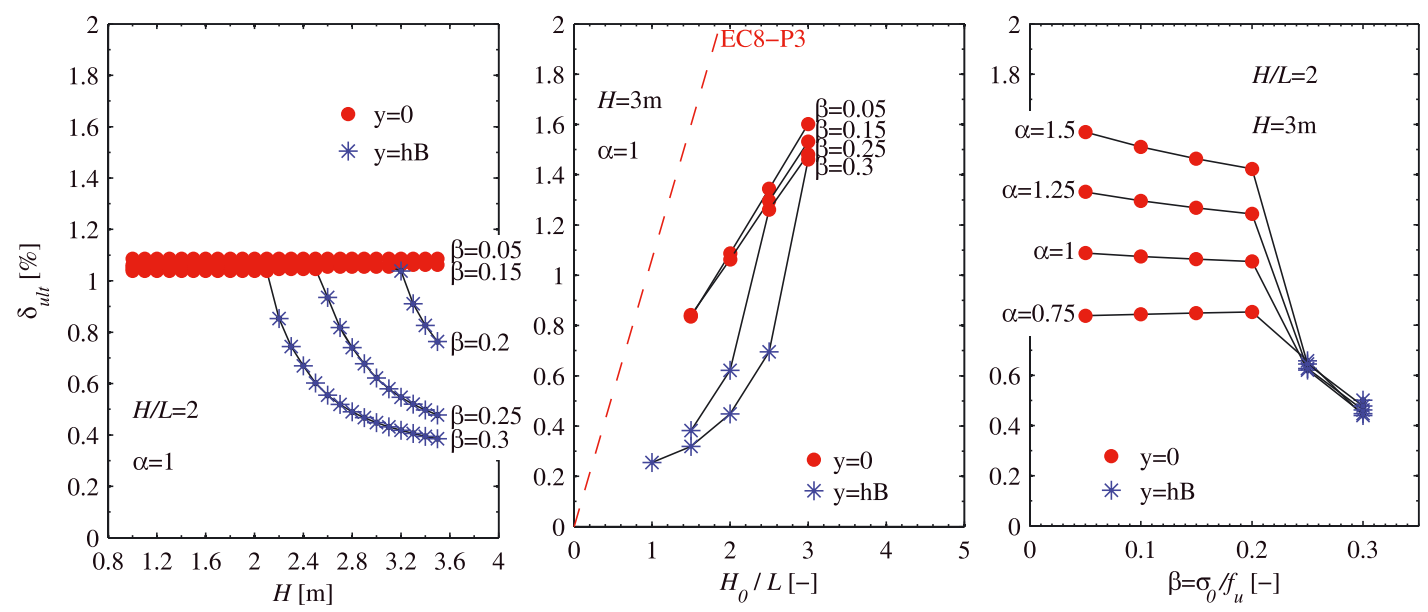

Figure 21. Predicted ultimate displacement capacity for flexure-dominated walls dependent on different parameters $\left(\alpha=H_{0} / H, \beta=\sigma_{0} / f_{u}\right)$. (a) $H$, (b) $H_{0} / L$ and (c) $\beta=\sigma_{0} / f_{u}$.

The two existing mechanical models (Benedetti and Steli [14] and Priestley et al. [12]) yield similar standard deviations as the new model, but the model by Benedetti and Steli [14] underestimates in average the displacement capacity significantly. It is based on limiting the stresses at the external fibre at the wall base to the compression strength of the masonry and neglects therefore any confining effect of the foundation [18]. The model by Priestley et al. [12] also determines the displacement capacity by considering the masonry strength at the base. However, neglecting the 
influence of the confining effect of the foundation as well as of the shear deformations seems compensated by the assumed curvature profile, that is, a linear profile over a height $\left(L-L_{c}\right)$, which could not be confirmed by experimental results (Figure 14).

\section{DETERMINANT PARAMETERS FOR THE ULTIMATE DRIFT CAPACITY}

The comparison with experimental results showed that the proposed model yields good estimates of the ultimate displacement capacity when the material parameters are known, that is, the $E$ modulus of the masonry, the compression strength of masonry and bricks. All these material properties can be easily determined from standard material tests, and in Figure 21, the new proposed model is used in order to determine the influence of key parameters on the ultimate displacement capacity of URM walls. The investigated parameters are the axial stress ratio $\left(\beta=\sigma_{0} / f_{u}\right)$, the ratio of height of zero moment to wall height $\left(\alpha=H_{0} / H\right)$, the shear span of the wall $\left(H_{0} / L\right)$ and the size of the wall $(H)$. The determining failure criterion, that is, whether failure is attained at the base $(y=0)$ or at the second joint $\left(y=h_{B}\right)$, is indicated by the colour of the marker. The parametric study considers only wall configurations, which would-according to EC8-P3 [11] - fail in flexure.

Figure 21(a) shows that for large walls $(H>2 \mathrm{~m})$ subjected to relatively large axial stresses, the failure will occur in the second joint before it can occur in the base joint. This confirms the influence of the wall size observed in [10] and reveals also the importance of considering the failure criteria at both the base and the second joint. Figure 21(b) shows that the drift capacity increases with increasing aspect ratio. If the failure is governed by the base joint, there is a linear relationship between drift capacity and aspect ratio-as it is predicted by EC8-P3 [11]. The size of the wall with respect to the size of the brick (here $l_{B}=0.3 \mathrm{~m}, h_{B}=0.2 \mathrm{~m}, f_{u}=6 \mathrm{MPa}, f_{c, B}=25 \mathrm{MPa}$ ) affects the local failure mechanism and influences therefore the trends. Figure 21(c) shows that for small axial stress ratios $\left(\sigma_{0} / f_{u} \leq 0.2\right)$, the influence of the axial stress ratio on the displacement capacity is negligible. However, for higher axial stress ratios, failure will occur in the second joint before it can occur in the base joint, resulting thus in smaller drift capacities for higher axial stresses.

\section{CONCLUSIONS AND OUTLOOK}

This article presents a new mechanical model for describing the force-displacement response up to the LS 'Near Collapse' of in-plane-loaded URM walls developing a flexural mode. The model is developed in two steps. First, an analytical formulation for the force-displacement response is derived, and second, local LSs that characterise the flexural failure are implemented. The new model allows therefore linking local LSs to global displacement capacities of modern URM walls with cement mortar and clay bricks.

The analytical formulation is based on the same hypotheses as the existing models for rocking URM walls [14-16], that is, plane-section hypothesis and a material with zero tensile strength and a linear elastic behaviour in compression. As a result, only the compressed part of the wall contributes to the resistance of the wall, and the model accounts for a softening of the response due to the reduction of the effective area after onset of decompression. Unlike the existing models, the new formulation accounts for the variation in effective area along the height of the wall. Further, it is assumed that not only the flexural stiffness but also the shear stiffness depends on the effective area and not the gross area. Validation against results from 34 wall tests showed that this leads to an improved prediction of the effective stiffness. For two wall tests, also detailed information on the displacement field was available, allowing therefore a more detailed validation. Comparison of experimental with predicted values showed that the model is able to predict not only the global response but also the contributions of shear and flexural deformations to the total displacement as well as compressive strains and shear strains.

In a second step, criteria for local LSs were developed and implemented. These new criteria address the LSs that are characterised by the splitting and crushing of the bricks in the compressed toe of the masonry wall and account also for the confining effect of the foundation. Apart from the wall geometry 
and boundary conditions (axial load and shear span), the model requires as input material parameters that can be obtained from standard material tests, for example, the stiffness and strength of the masonry as well as the brick strength. If these material properties are known, the model yields a better prediction of the displacement capacity than any of the existing empirical or mechanical models. The model confirms that the drift capacity of walls failing in a flexural mode depends on the axial stress ratio and the ratio of shear span to height, which are key parameters in empirical models. The model further shows that there is indeed a size effect on the drift capacity of the wall; that is, the drift capacity of walls constructed with the same brick size is dependent on the size of the wall. This results from (i) the confining effect of the foundation, (ii) the resulting observation that splitting of bricks initiates at the second joint half a brick inwards from the extreme fibre and (iii) that plastic deformations spread over at least over the height of one brick.

Research on mechanical drift capacity models for URM walls is still at the beginning, and before such models can be implemented in codes, many topics require further research. First and foremost, a drift capacity model for URM walls failing in shear is required, but also other topics such as the effect of different construction materials, wall sections, cumulative damage demands and strain rates need to be investigated and their effect on the force-displacement response and the displacement capacity incorporated in the mechanical drift capacity models.

\section{ACKNOWLEDGEMENTS}

We would like to thank Prof. Andrea Penna, University of Pavia, Italy, for his helpful comments, our colleague Shenghan Zhang who modelled the walls from the PUP series in Vector2 and helped us thus to confirm our results, our colleague Francesco Vanin who double-checked and implemented the model in a MATLAB file, our colleague Bastian Wilding for his comments and suggestions, and Dr Suikai Lu, a consulting engineer from Vienna, who gave us indications on the possible range of compression strengths for clay masonry bricks. We further thank two anonymous reviewers for their comments and suggestions.

\section{REFERENCES}

1. Magenes G. Masonry building design in seismic areas: recent experiences and prospects from a European standpoint. Keynote lecture at the First European Conference on Earthquake Engineering and Seismology, Geneva, Switzerland, 2006.

2. Magenes G, Calvi GM. In-plane seismic response of brick masonry walls. Earthquake Engineering and Structural Dynamics 1997; 26(11):1091-1112. DOI:10.1002/(SICI)1096-9845(199711)26:11<1091::AID-EQE693>3.0.CO;2-6.

3. Turnšek V, Cašovič F. Some experimental results on the strength of brick masonry walls. In: Proceedings of the Second International Brick Masonry Conference 1971: 149-156.

4. Turnšek V, Sheppard P. The shear and flexural resistance of masonry walls. In: Proceedings of the International Research Conference on Earthquake Engineering 1981; 517-573.

5. Mann W, Müller H. Failure of shear-stressed masonry - an enlarged theory, tests and application to shear walls. In: Proceedings of the British Ceramic Society 1982; Vol. 30: 223-235.

6. Ganz HR. Mauerwerksscheiben unter Normalkraft und Schub. PhD Thesis, ETH Zürich, Switzerland, 1985.

7. Beyer K, Petry S, Tondelli M, Paparo A. Towards displacement-based design of modern unreinforced masonry structures. Perspectives on European Earthquake Engineering and Seismology, Ansal A (ed.). Springer: Istanbul, Turkey, 2014.

8. Lang K. Seismic vulnerability of existing buildings. PhD Thesis, ETH Zürich, Switzerland, 2002.

9. Pfyl-Lang K, Braune F, Lestuzzi P. SIA D0237: Evaluation de la sécurité parasismique des bâtiments en maçonnerie. Documentation, Swiss Society of Engineers and Architects SIA: Zürich, Switzerland, 2011 [in French].

10. Petry S, Beyer K. Influence of boundary conditions and size effect on the drift capacity of URM walls. Engineering Structures 2014; 65:76-88. DOI:10.1016/j.engstruct.2014.01.048.

11. CEN. Eurocode 8: Design of Structures for Earthquake Resistance - Part 3: Assessment and Retrofitting of Buildings, Design Code EN 1998-3: 2005. European Committee for Standardization (CEN): Brussels, Belgium, 2005.

12. Priestley MJN, Calvi GM, Kowalsky MJ. Direct Displacement Based Design. IUSS PRESS: Pavia, 2007.

13. Heyman J. Leaning towers. Meccanica 1992; 27:153-159.

14. Benedetti A, Steli E. Analytical models for shear-displacement curves of unreinforced and FRP reinforced masonry panels. Construction and Buildings Materials 2008; 22(3):175-185. DOI:10.1016/j.conbuildmat.2006.09.005.

15. Benedetti A, Benedetti L. Interaction of shear and flexural collapse modes in the assessment of in-plane capacity of masonry walls. In: Proceedings of the 12th Canadian Masonry Symposium, Vancouver, Canada, 2013.

16. Penna A, Lagomarsino S, Galasco A. A nonlinear macroelement model for the seismic analysis of masonry buildings. Earthquake Engineering and Structural Dynamics 2014; 43(2):159-179. DOI:10.1002/eqe.2335.

17. Lagomarsino S, Penna A, Galasco A, Cattari S. TREMURI program: an equivalent frame model for the nonlinear seismic analysis of masonry buildings. Engineering Structures 2013; 56:1787-1799. DOI:10.1016/j.engstruct.2013.08.002. 
18. Petry S, Beyer K. Flexural deformations of URM piers: comparison of analytical models with experiments. In: Proceedings of the $9^{\text {th }}$ International Masonry Conference, Guimarães, Portugal, 2014.

19. Gambarotta L, Lagomarsino S. Damage models for the seismic response of brick masonry shear walls. Part I: the mortar joint model and its applications. Earthquake Engineering and Structural Dynamics 1997; 26(4):423-439.

20. Petry S, Beyer K. Limit states of URM walls subjected to seismic in-plane loading. Submitted to Bulletin of Earthquake Engineering February 2014.

21. Petry S, Beyer K. Cyclic test data of six unreinforced masonry walls with different boundary conditions. Earthquake Spectra 2014. DOI:10.1193/101513EQS269.

22. CEN. Eurocode 6: Design of Masonry Structures - Part 1-1: General Rules for Reinforced and Unreinforced Masonry Structures, Design Code EN 1996-1-1:2005. European Committee for Standardization (CEN): Brussels, Belgium, 2005.

23. Tomaževič M. Shear resistance of masonry walls and Eurocode 6: shear versus tensile strength of masonry. Materials and Structures 2009; 42:889-907. DOI:10.1617/s11527-008-9430-6.

24. Costa A, Penna A, Magenes G. Seismic performance of autoclaved aerated concrete (AAC) masonry: from experimental testing of the in-plane capacity of walls to building response simulation. Journal of Earthquake Engineering 2011; 15(1):1-31.

25. Frumento S, Magenes G, Morandi P, Calvi GM. Interpretation of Experimental Shear Tests on Clay Masonry Walls and Evaluation of q-Factors for Seismic Design. Technical Report, IUSS Press: Pavia, 2009. 